\title{
A reductive coupling strategy towards ripostatin A
}

\author{
Kristin D. Schleicher and Timothy F. Jamison *
}

\section{Full Research Paper}

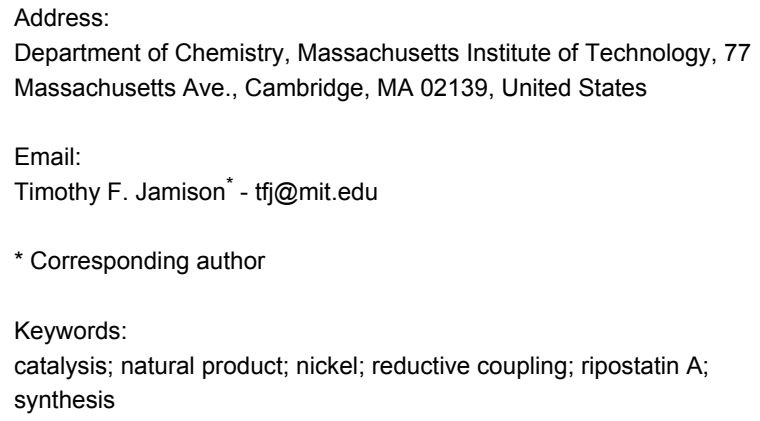

Beilstein J. Org. Chem. 2013, 9, 1533-1550.

doi:10.3762/bjoc. 9.175

Received: 01 May 2013

Accepted: 04 July 2013

Published: 31 July 2013

This article is part of the Thematic Series "Transition-metal and organocatalysis in natural product synthesis".

Guest Editors: D. Y.-K. Chen and D. Ma

(C) 2013 Schleicher and Jamison; licensee Beilstein-Institut. License and terms: see end of document.

\begin{abstract}
Synthetic studies on the antibiotic natural product ripostatin A have been carried out with the aim to construct the C9-C10 bond by a nickel(0)-catalyzed coupling reaction of an enyne and an epoxide, followed by rearrangement of the resulting dienylcyclopropane intermediate to afford the skipped 1,4,7-triene. A cyclopropyl enyne fragment corresponding to $\mathrm{C} 1-\mathrm{C} 9$ has been synthesized in high yield and demonstrated to be a competent substrate for the nickel(0)-catalyzed coupling with a model epoxide. Several synthetic approaches toward the $\mathrm{C} 10-\mathrm{C} 26$ epoxide have been pursued. The $\mathrm{C} 13$ stereocenter can be set by allylation and reductive decyanation of a cyanohydrin acetonide. A mild, fluoride-promoted decarboxylation enables construction of the $\mathrm{C} 15-\mathrm{C} 16$ bond by an aldol reaction. The product of this transformation is of the correct oxidation state and potentially three steps removed from the targeted epoxide fragment.
\end{abstract}

\section{Introduction}

The ripostatins (A, B, and C) are a family of antibiotic natural products, isolated in 1995 by Höfle and colleagues from cultures of the myxobacterium Sorangium cellulosum (Figure 1) $[1,2]$. Ripostatins A and B are active against Gram-positive bacteria due to their inhibition of bacterial ribonucleic acid polymerase. These compounds inhibit chain initiation of RNA synthesis in Staphylococcus aureus, a particularly infectious bacterial strain with reported drug resistance to the antibiotics vancomycin and methicillin [3]. Ripostatin A exists as an equilibrium mixture of ketone and hemiketal forms, the ratio of which is reported to be 55:45 in methanolic solution. In the hemiketal form, the bicyclic framework of ripostatin A features an unusual in/out connectivity. The 14-membered macrocyclic core of ripostatin A contains three double bonds, arranged in a rare 1,4,7-skipped triene. The alkene geometry was determined to be $(2 E, 5 E, 8 E)$ by measurement of NOE enhancements [4]. 
Ripostatin B and its C15 epimer can be obtained from ripostatin A by reduction with sodium borohydride, while ripostatin $\mathrm{C}$ can be formed from ripostatin A by a mild base-mediated elimination. Consequently, ripostatin $\mathrm{A}$ was selected as the primary target for synthesis.

At the outset of our efforts, the only published synthetic study on the ripostatins was Kirschning's synthesis of $\mathrm{C} 1-\mathrm{C} 5$ and C6-C24 fragments of ripostatin B [5]. However, these fragments could not be connected by esterification due to steric hindrance from bulky protecting groups, as well as susceptibility of the skipped dienes therein to double bond isomerization and migration under basic conditions. However, the ripostatins intrigued others, and three total syntheses of ripostatin B were published in succession in 2012 [6-8]. Tang and Prusov extended their synthetic method to syntheses of 15-deoxyripostatin A, and later ripostatin A itself [9]. All of these approaches to the ripostatins share several key features: use of ring-closing metathesis to form the 14-membered macrocycle, preceded by one or more Stille couplings to generate the double 1,4-diene (Figure 2).

Notwithstanding the successful syntheses of ripostatins, preparation of configurationally defined skipped polyenes (1,4-dienes and higher homologues) remains a significant challenge in organic chemistry. The doubly allylic protons found in these structures may be sensitive to strong base as well as hydrogen abstraction $[10,11]$. While classical methods for the preparation of 1,4-dienes include partial reduction of alkynes and carbonyl olefination, a variety of transition-metal-mediated processes have been developed for the synthesis of skipped dienes of varied substitution patterns [12-15]. Most recently, Sigman and colleagues have reported a palladium-catalyzed 1,4-difunctionalization of 1,4-butadiene with vinylboronic acid and vinyl triflate that can be used to rapidly access the skipped triene of ripostatin $\mathrm{A}[16]$.<smiles>C=CCCC(C)=CCC=CCC(=CC(=O)OC(CC(=O)O)CC(=O)CCC(C)=CCc1ccccc1)C[C@@H](O)CC(=O)O</smiles>

ripostatin $A(1)$, ketone form<smiles>CC(=CCC=CCC(=CC(=O)O)CC(=O)O)CC[C@H](O)CC(CC(O)CC(C)=CCc1ccccc1)OC(=O)O</smiles>

ripostatin B (2)

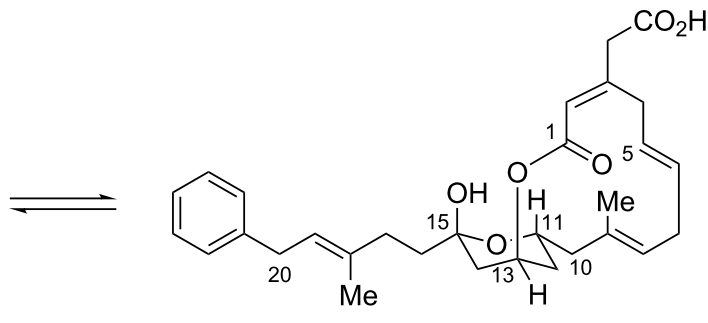

ripostatin $\mathrm{A}$, hemiketal form<smiles>CC(=CCC=CCC(=CC(=O)O)CC(=O)O)CC(O)CCC(=O)CCC(C)CCc1ccccc1</smiles>

Figure 1: Structures of the ripostatins.

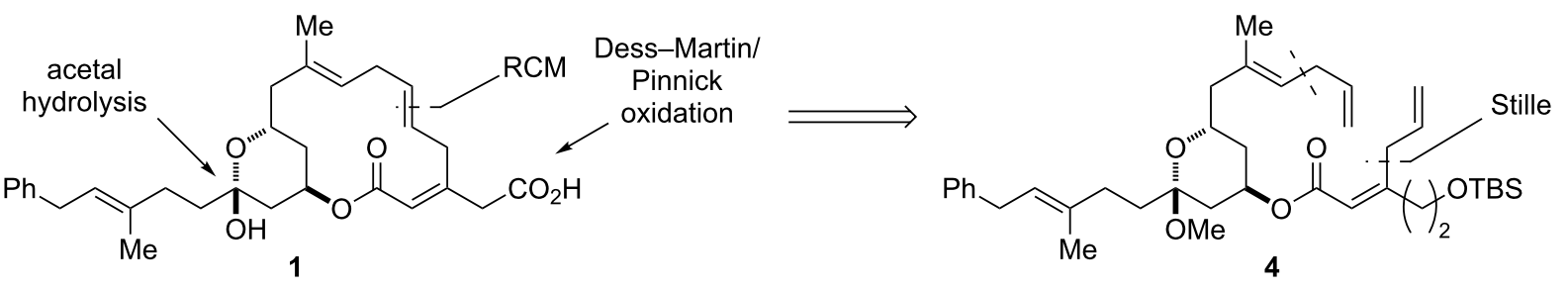

Figure 2: Retrosynthesis of ripostatin A. 
We recognized that the $\mathrm{C} 11$ stereocenter and the C8-C9 trisubstituted olefin of ripostatin A mapped onto a nickel-catalyzed coupling reaction of alkynes and epoxides developed in our laboratory (Scheme 1) [17]. In the intermolecular reaction, stereospecific cis addition across the alkyne is observed, and the stereochemistry at the epoxide is preserved in the transformation. Aliphatic epoxides are opened selectively (>95:5) at the terminal position. Although very high regioselectivity with respect to the alkyne is observed when $\mathrm{R}^{1}=\mathrm{Ph}$ and $\mathrm{R}^{2}=\mathrm{Me}$, attempts to differentiate between aliphatic alkyne substituents lead to mixture of regioisomers. When a 1,3-enyne is coupled with simple epoxides, however, $>95: 5$ regioselectivity is observed for $\mathrm{C}-\mathrm{C}$ bond formation distal to the pendant alkene [18].

In conjunction with the nickel-catalyzed fragment coupling, we wished to investigate whether it would be possible to delay introduction of the potentially sensitive 1,4,7-triene by masking it as a cyclopropyldiene, then unveiling the skipped triene portion via a 1,5-hydrogen rearrangement (Figure 3). This strategy would allow us to take advantage of the high regioselectivity in enyne-epoxide reductive coupling reactions. Furthermore, the proposed rearrangement would serve to differentiate the ester groups, as hydrogen would migrate from adjacent to the ester cis to the dienyl chain only.

While offering a unique approach to the skipped triene portion of ripostatin, this route was not without significant uncertainty. First, substrates containing a vinyl cyclopropane unit had not been previously tested under nickel-catalyzed reductive coupling conditions. Nickel( 0$)$ is known to catalyze the rearrangement of vinylcyclopropanes to cyclopentenes; however, activating substituents are commonly required [1921]. Furthermore, application of a proposed 1,5-hydrogen rearrangement to ripostatin $A$ would require that the reaction proceed to give the triene with $E, E, E$ configuration selectively out of four possible configurational outcomes (Scheme 2).
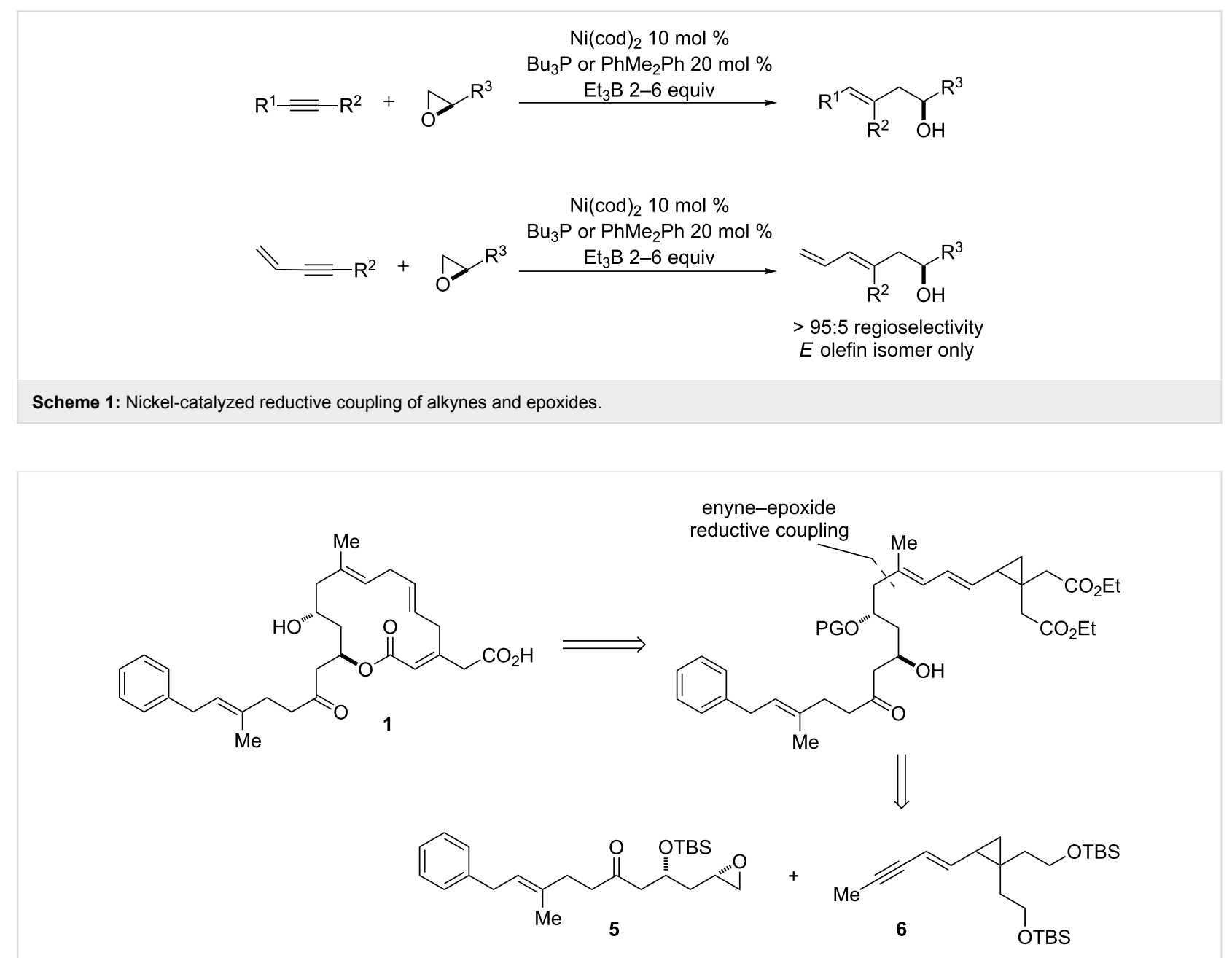

Figure 3: Proposed retrosynthesis of ripostatin A featuring enyne-epoxide reductive coupling and rearrangement. 


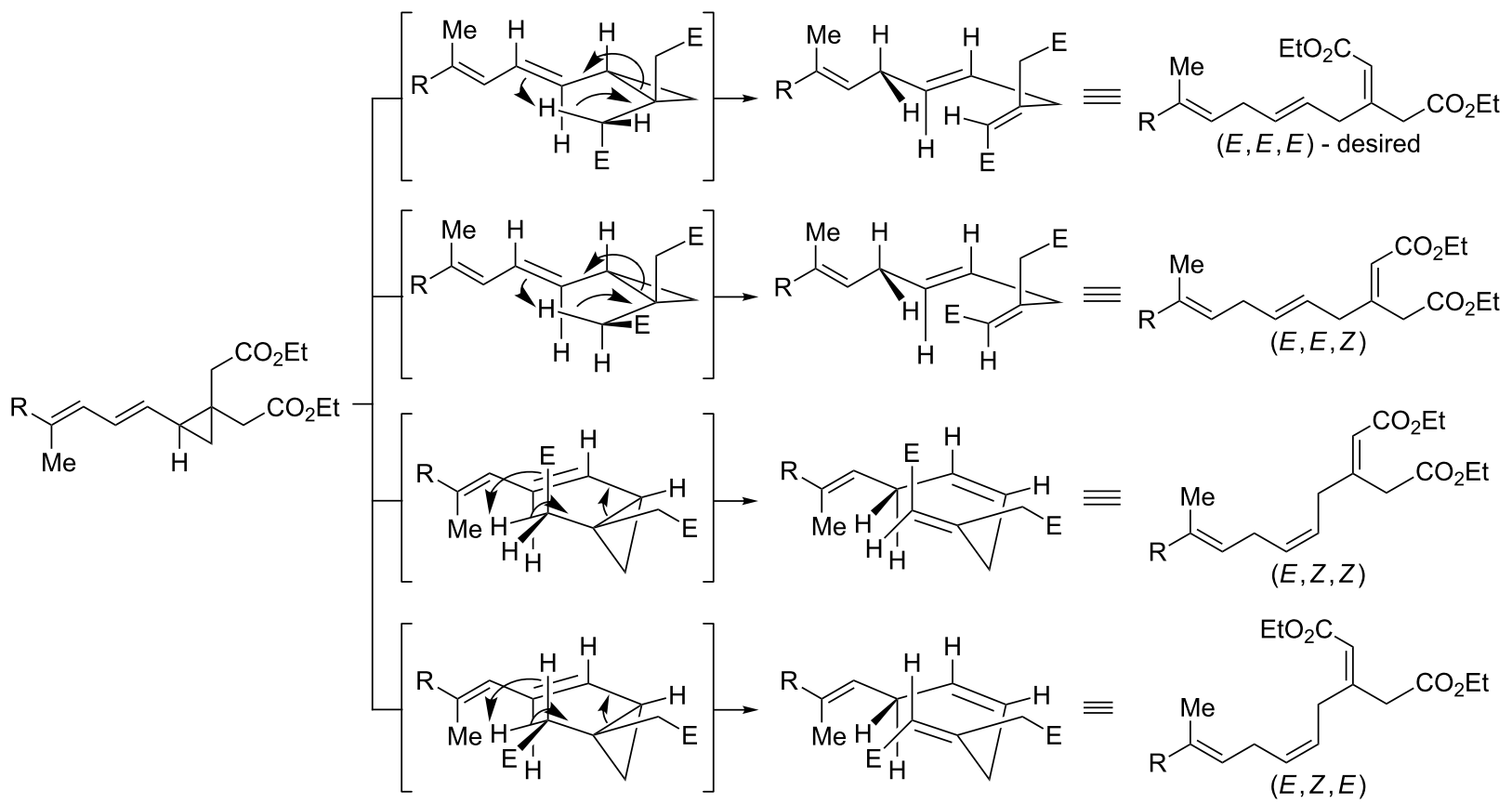

Scheme 2: Potential transition states and stereochemical outcomes for a concerted 1,5-hydrogen rearrangement.

Rearrangement of vinylcyclopropanes has been used to prepare 1,4-skipped dienes of varying geometry (Scheme 3). It has long been known that cis-disubstituted vinylcyclopropanes can undergo 1,5-hydrogen migration under thermal conditions to deliver acyclic 1,4-dienes [22]. In this reaction manifold, the new "acceptor-derived" double bond is formed via an endo transition state, leading to a cis olefinic configuration in the product (Scheme 3, reaction 1). Berson has quantified the energetic preference in this transformation, while Turos has shown that the presence of a silicon substituent on the "donor carbon" facilitates the hydrogen migration [23-26].

In contrast, Wilson has reported formation of the trans double bond in the opening of a cyclopropane with an adjacent hydroxy or mesylate leaving group, regardless of the initial configuration of the cyclopropane (Scheme 3, reaction 2) [27]. Braddock has demonstrated that the internal 3,4-E olefin is obtained exclusively in Prins reactions terminated by cyclopropylmethylsilane (Scheme 3, reaction 3), which may be explained by the participation of a carbocation that is stabilized by the adjacent cyclopropane ring in the bisected conformation where (CHOR)R' is oriented anti to the cyclopropane [28-30]. Finally, Micalizio has described a titanium-mediated, alkoxidedirected fragment coupling reaction between vinylcylopropanes and vinyldimethylchlorosilane (Scheme 3 , reaction 4) in which the stereochemical outcome of the rearrangement is orches- trated by the adjacent alkoxide, which is believed to direct formation of a tricyclic titanacyclopentane that subsequently fragments in a stereospecific manner [31].

We were intrigued by the apparent difference in selectivity observed in cyclopropane rearrangements proceeding via a neutral pathway versus those proceeding by more polar or directed mechanisms. Although the $E$ geometry of the central olefin in the ripostatin A triene is more consistent with a polar mode of reactivity than a neutral 1,5-hydrogen migration, we still wished to investigate the outcome of rearrangement under thermal conditions. To the best of our knowledge, such a rearrangement has not been explored for structures containing an additional alkenyl substituent in conjugation, or with electron-withdrawing groups adjacent to the site of hydrogen migration. In particular, the latter's ability to facilitate the buildup of negative charge at an adjacent carbon might play an important role in the stereoelectronic course of the reaction.

\section{Results and Discussion Synthesis of cyclopropylenyne and reductive coupling with model epoxide}

Diethyl 1,3-acetonedicarboxylate (Scheme 4, 16) was rapidly identified as an inexpensive five-carbon fragment possessing the appropriate oxygenation pattern for preparation of the C1-C9 enyne fragment. However, due to keto-enol tautomer- 
Berson:

(1)

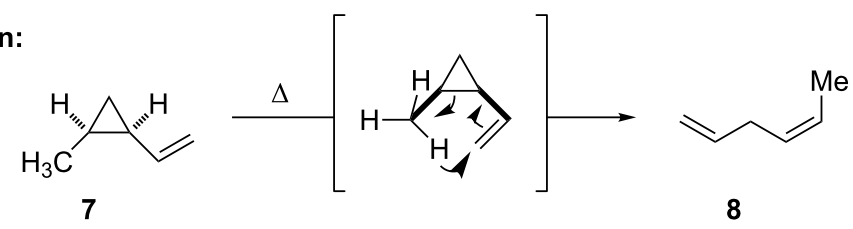

Wilson:

(2)
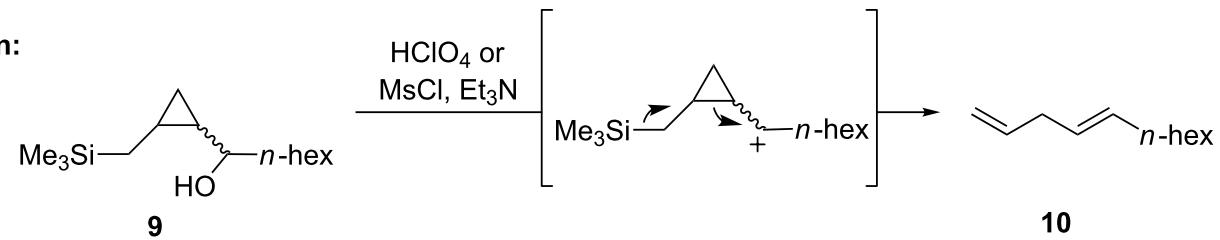

Braddock:

(3)

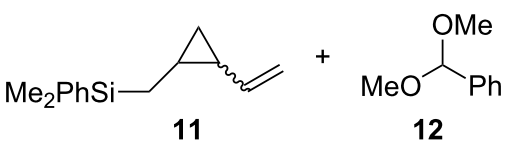

TMSOTf,

10<smiles>CC(C)(C)c1cccc(C(C)(C)C)n1</smiles>

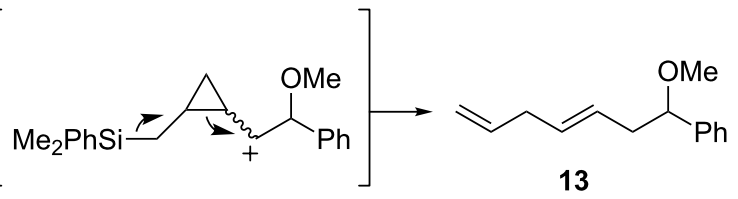

Micalizio:

(4)

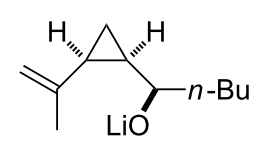

14

$$
\begin{gathered}
\mathrm{ClTi}(\mathrm{OiPr})_{3}, \\
\mathrm{c}-\mathrm{C}_{5} \mathrm{H}_{9} \mathrm{MgCl}
\end{gathered}
$$

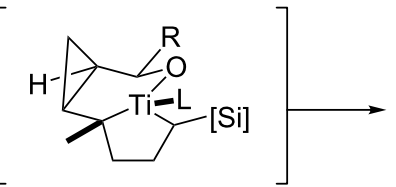

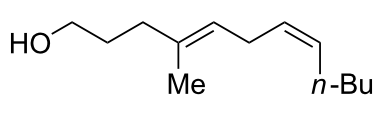

15

Scheme 3: Rearrangements of vinylcyclopropanes to acylic 1,4-dienes.

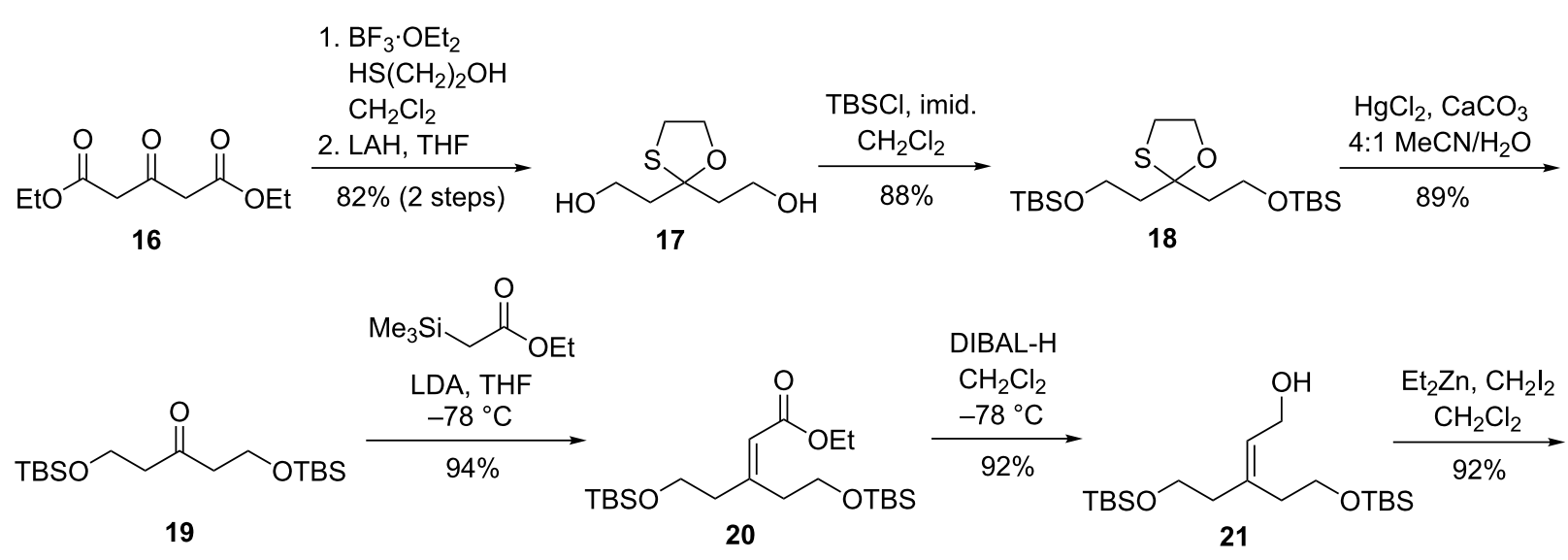

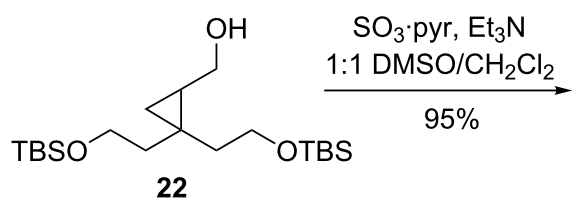<smiles>CC(C)(C)OCCC1(CC[O+]S)CC1C=O</smiles>

1. $\mathrm{CrCl}_{2}, \mathrm{CHI}_{3}, \mathrm{THF} 79 \%$

2. $\mathrm{Pd}\left(\mathrm{PPh}_{3}\right)_{4}, \mathrm{Cul}, \mathrm{iPr}_{2} \mathrm{NH}$ propyne, THF

$-30{ }^{\circ} \mathrm{C} 92 \%, 15: 1 \mathrm{E} / \mathrm{Z}$

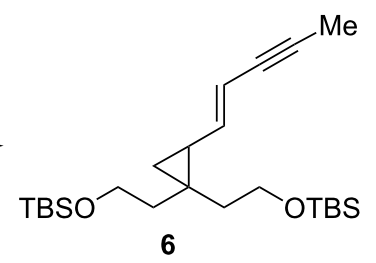

Scheme 4: Synthesis of cyclopropyl enyne. 
ization, carbonyl olefination methods are of limited utility for this substrate. Instead, the ketone was protected as the mixed $S, O$-ketal and reduced to the diol 17. Protection of the hydroxy groups and removal of the ketal afforded ketone 19. A number of alternative promoters were investigated to avoid the use of mercury(II) salts in the ketal deprotection (including MeI, $\mathrm{H}_{2} \mathrm{O}_{2}, \mathrm{AgClO}_{4} / \mathrm{I}_{2}$ ); however, these generally led to concomitant removal of the TBS groups.

Ketone 19 was converted to the $\alpha, \beta$-unsaturated ester $\mathbf{2 0}$ using the Peterson olefination [32]. Treatment of $\mathbf{2 0}$ with the sulfur ylide derived from trimethylsulfoxonium iodide $[33,34]$ led to recovery of starting material at room temperature, but decomposition at elevated temperatures. Instead, the enone was smoothly reduced to the allylic alcohol, and a Furukawa-modified Simmons-Smith reaction [35] afforded the cyclopropyl alcohol 22 in high yield.

Oxidation to the cyclopropyl aldehyde 23 offered a branching point from which either the $E$ - or $Z$-substituted enyne could be synthesized, should we wish to study the rearrangement of both diene geometries. To access our initial target, the $E$-enyne 6, a Takai olefination [36] was used to generate the $E$-vinyl iodide. The vinyl iodide was sufficiently stable for purification by silica gel chromatography but, following purification, was immediately carried forward to a Sonogashira reaction with propyne [37]. The enyne could be obtained in $15: 1 \mathrm{E} / \mathrm{Z}$ selectivity, in 10 steps and $35 \%$ overall yield. It was found that the use of freshly distilled THF in the Takai olefination and careful temperature control in the subsequent cross coupling were critical to the preservation of high $E / Z$ selectivity over the course of these transformations. Once isolated, however, enyne 6 proved to be quite stable and could be stored for extended periods at $0-5{ }^{\circ} \mathrm{C}$ without appreciable isomerization or decomposition.

With a suitable cyclopropylenyne in hand, a model epoxide substrate containing the 1,3-oxygenation pattern found in ripostatin A (Scheme 5) was prepared by using a route analo- gous to one reported by Smith [38]. Allylation of 24 with (+)-Ballyldiisopinocampheylborane generated the alcohol 25 in high yield and enantioselectivity. Directed epoxidation using $\mathrm{VO}(\mathrm{acac})_{2}$ and tert-butyl hydroperoxide was initially performed in order to furnish $\mathbf{2 7}$ directly; however, this proceeded in only modest yield and diastereoselectivity (53\%, 2.8:1 syn/anti). Although the ratio of syn/anti epoxide diastereomers could be enhanced by subjecting the mixture to hydrolytic kinetic resolution [39], greater throughput could be obtained by converting 25 to the tert-butyl carbonate, performing an iodocyclization, then cleaving the iodocarbonate and closing the epoxide under basic conditions. Silyl protection of the secondary alcohol afforded the desired model compound $\mathbf{2 8}$.

Enyne $\mathbf{6}$ and epoxide 28 were subjected to standard nickelcatalyzed reductive coupling conditions, and reductive coupling proceeded in good yield, leaving the cyclopropane ring intact (Scheme 6). However, the desired diene 29 was isolated along with the regioisomeric product $\mathbf{3 0}$ in approximately a 3:1 ratio. The desired product could be partially separated from the regioisomer by careful silica gel chromatography.

It may be instructive at this stage to consider the proposed mechanism of the nickel-catalyzed alkyne or enyne-epoxide reductive coupling reaction (Scheme 7). In contrast to the mechanistic framework proposed $[40,41]$ for reductive coupling reactions of alkynes and aldehydes developed in our laboratory $[42,43]$, it is believed that epoxide oxidative addition precedes alkyne addition, as opposed to concerted oxidative coupling. At least when dimethylphenylphosphine is used as ligand, this may proceed via the intermediacy of a betaine species. In the reductive coupling reaction of enynes and epoxides, the olefin coordinates to nickel and directs alkyne insertion.

Because of this directing effect, formation of the regioisomeric diene product is atypical for reductive coupling reactions of enynes and epoxides. However, in reactions of 1-phenyl-1propyne and epoxides with oxygenation in the 3-position

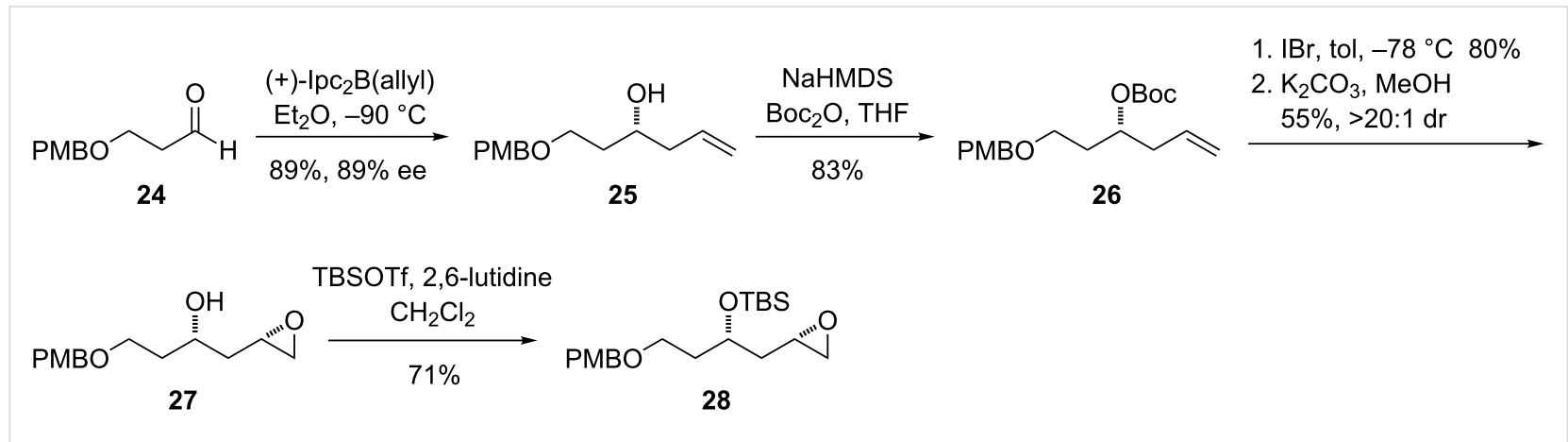

Scheme 5: Synthesis of model epoxide for investigation of the nickel-catalyzed coupling reaction. 

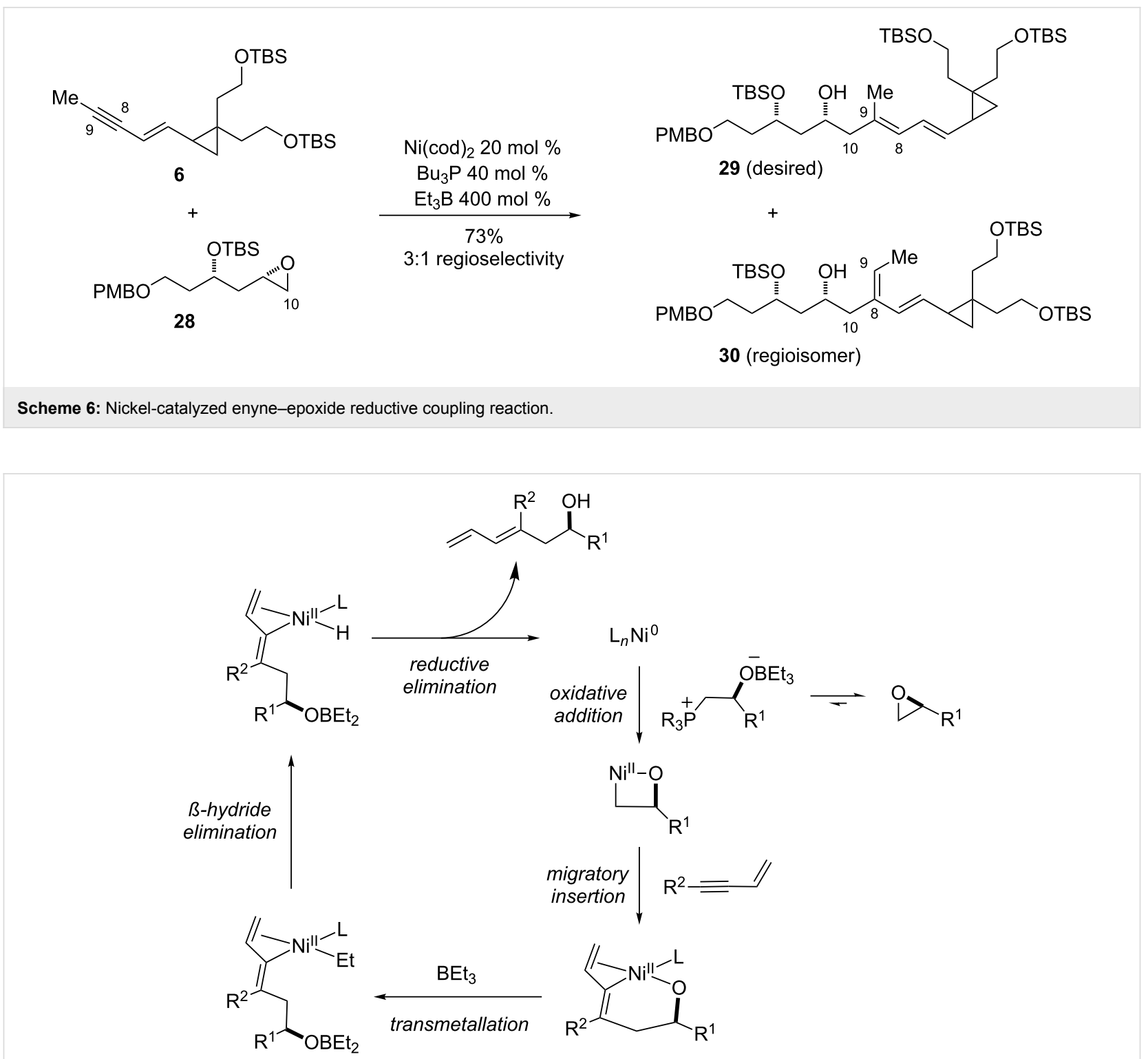

Scheme 7: Proposed mechanism for the nickel-catalyzed coupling reaction of alkynes or enynes with epoxides.

(Scheme 8), it was found that while epoxides containing adjacent silyl ethers afforded mainly the expected regioisomer (7:1 37a/37b), epoxides with sulfonate esters (e.g., tosyl, 32) and esters (e.g., acetyl, 33) afforded a regioisomeric mixture of opposite (albeit poor) selectivity relative to that normally observed for unfunctionalized epoxides [44]. This is proposed to be an effect of the coordinating ability of Lewis basic oxygen atoms in tosylates and esters, which may disrupt the binding and directing effect of phenyl or alkenyl groups.

In the case of the ripostatin A model system, the most likely candidate for chelation is the oxygen protected as the PMB ether. Although an eight-membered chelate might seem too large to play an important role in directing regioselectivity, the
3:1 regioselectivity observed in the "normal" direction is consistent with chelation playing a diminished role relative to the seven-membered chelates invoked for coupling of 3-oxygenated epoxides. We attempted to discern whether this interaction was the reason for the observed regioselectivity by performing the nickel-catalyzed coupling reaction with 1,2epoxyoctane, which lacks potentially chelating functional groups (Scheme 9). Although the coupling product 39 appears to be formed in the reaction with either $\mathrm{Bu}_{3} \mathrm{P}$ or $\mathrm{PhMe}_{2} \mathrm{P}$ as ligand, the non-polar nature of this molecule complicates chromatographic purification, and mixtures of what appears to be 39 along with one or more other products were obtained. Based on these results, regioisomer formation cannot be excluded. 


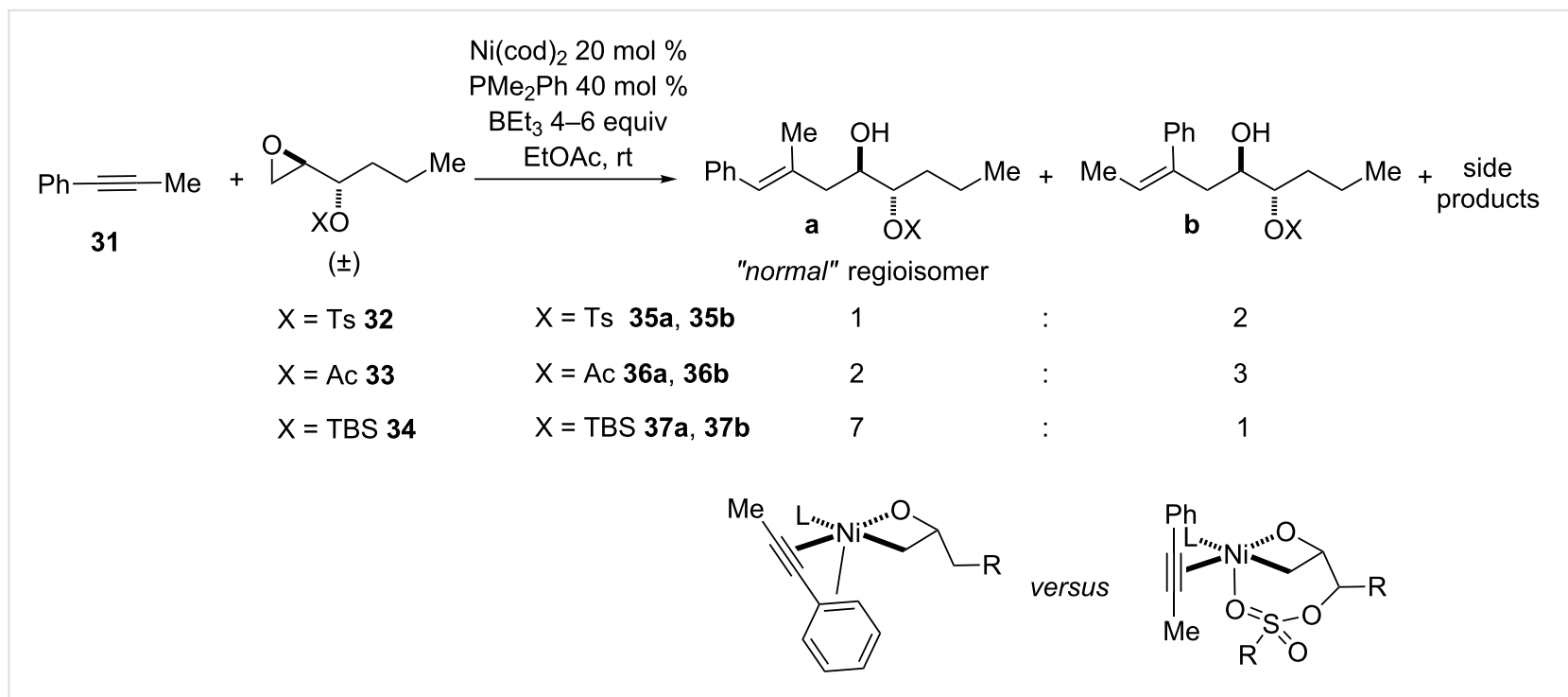

Scheme 8: Regioselectivity changes in reductive couplings of alkynes and 3-oxygenated epoxides.
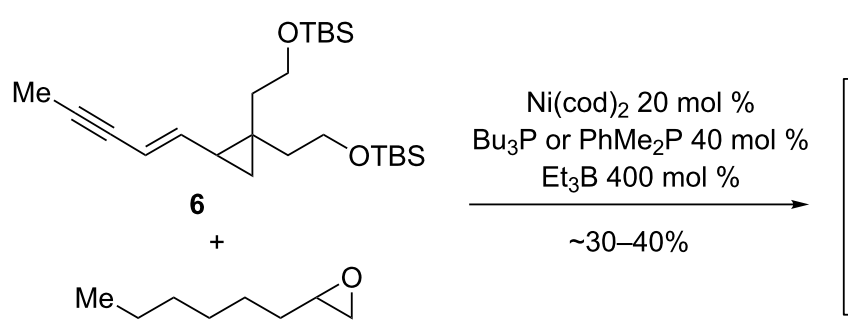

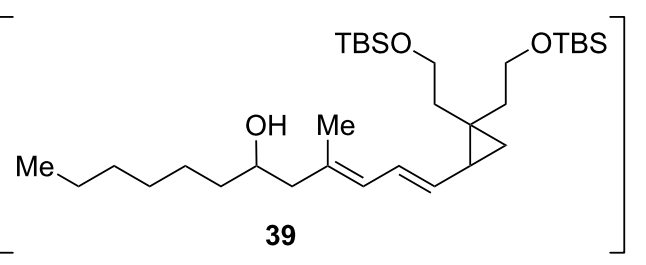

38

Scheme 9: Enyne reductive coupling with 1,2-epoxyoctane.

Several aspects of the enyne synthesis and the nickel-catalyzed coupling reaction require further investigation. As 6 does not itself appear to undergo thermal rearrangement, it seems advantageous to convert this compound to the corresponding diester. Preliminary investigation indicates that oxidation of the diol derived from 6 is complicated by the 1,5-relationship of the alcohols. Despite the greater complexity inherent to this alter- native, differentiation of the alcohols allowing for sequential oxidation may be necessary.

\section{Dithiane approach to epoxide}

With respect to the synthesis of the proposed epoxide fragment 5, we initially envisioned using the reaction of lithiated dithianes with epoxides (Figure 4) [45-49]. We reasoned that 41<smiles></smiles>

42

Figure 4: Initial retrosynthesis of the epoxide fragment by using dithiane coupling. 
could be expediently accessed from the corresponding aldehyde by making use of a Claisen rearrangement to set the geometry of the $\gamma, \delta$-unsaturated double bond.

In the forward direction, the allylic alcohol 44 was obtained from reaction of the alkenyllithium reagent derived from 2-bromopropene with phenylacetaldehyde (Scheme 10). In our hands, the organolithium afforded significantly higher and more reproducible yields than either the commercially available Grignard reagent or the organocerium. Johnson-Claisen rearrangement [50] of $\mathbf{4 4}$ proceeded smoothly to give the $\gamma, \delta$ unsaturated ester 45. Conducting the reaction without added solvent in a microwave reactor at $170{ }^{\circ} \mathrm{C}$ allowed the reaction to proceed in just 30 minutes; a significant improvement over heating the reaction mixture in toluene under reflux, which typically required 48 hours to obtain a comparable yield. Reduction and oxidation afforded the aldehyde $\mathbf{4 7}$, which could then be converted to dithiane $\mathbf{4 1}$.

Unfortunately, attempts to couple $\mathbf{4 1}$ with an oxygenated epoxide fragment under a variety of conditions reported by Smith for lithiation and electrophilic trapping [51] were unsuccessful. We suspected that the lithiated dithiane was not being generated and decided to investigate this step of the reaction independently of reaction with the epoxide electrophile. To this end, 41 was treated with tert-butyllithium at $-78{ }^{\circ} \mathrm{C}$ in a $90: 10$ THF/HMPA mixture, referred to as the method of first choice for lithiation of complex dithianes (Scheme 11). Following warming to $-42{ }^{\circ} \mathrm{C}$, the reaction was quenched with deuterated methanol. Analysis of the product by ${ }^{1} \mathrm{H}$ NMR revealed that no deuterium incorporation (to the sensitivity of integration) had occurred at the desired dithiane site, while approximately $80 \%$ deuterium incorporation had occurred at the allylic/benzylic site.

These results indicated that the presence of the trisubstituted C18-C19 olefin would interfere with dithiane coupling. However, given the suitability of the Claisen rearrangement for formation of this bond, we wished to preserve that transformation. Accordingly, an alternate route that would capitalize on the electrophilic nature of aldehyde $\mathbf{4 7}$ to form the bond corresponding to $\mathrm{C} 14-\mathrm{C} 15$ of ripostatin $\mathrm{A}$ instead was sought.

\section{Oxy-Michael approach to epoxide}

We were intrigued by a recent report by Falck describing an organocatalytic oxy-Michael addition to achiral $\delta$-hydroxy- $\alpha, \beta$ -

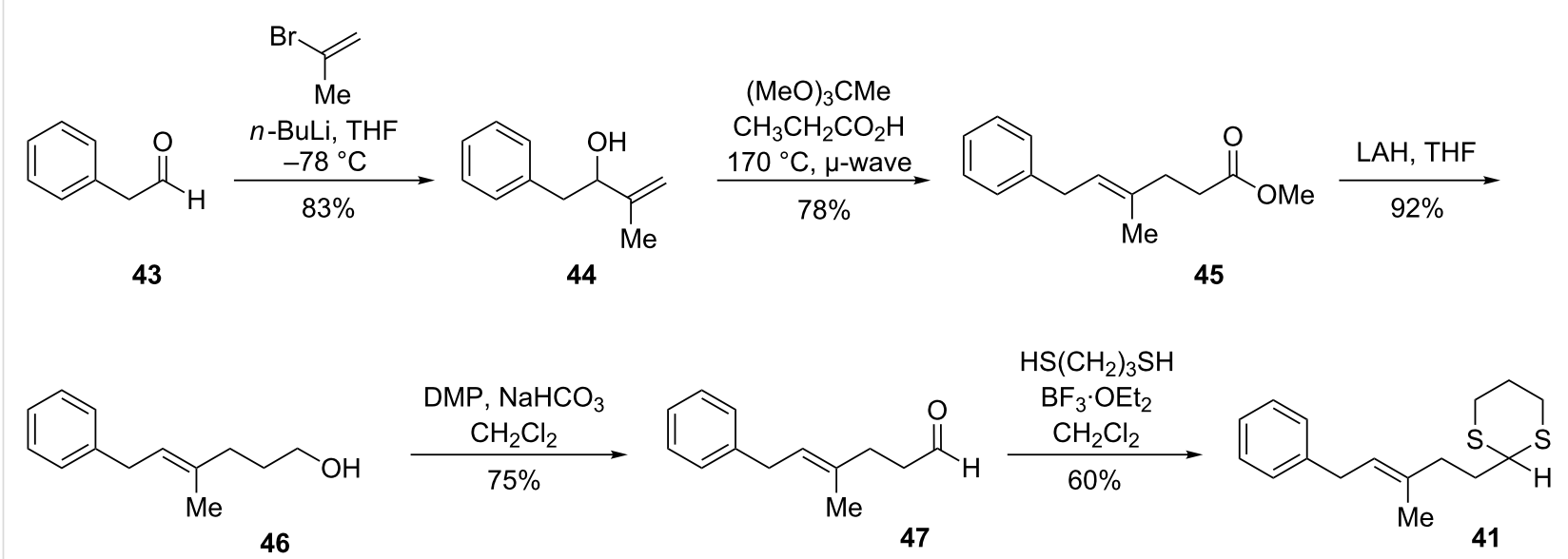

Scheme 10: Synthesis of dithiane by Claisen rearrangement.

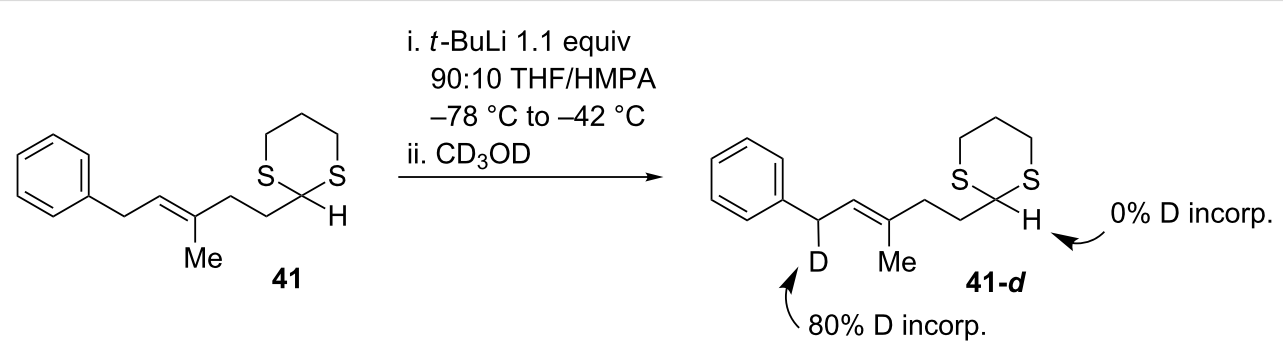

Scheme 11: Deuterium labeling reveals that the allylic/benzylic site is most acidic. 
enones (Scheme 12) [52]. The hydroxy group is delivered in a directed fashion from the boronic acid hemiester generated in situ from the substrate and phenylboronic acid. It is proposed that complexation of the tertiary nitrogen to boron and coordination of the carbonyl act in a push/pull fashion, simultaneously enhancing the nucleophilicity of the boronate oxygen as well as imposing a chiral environment around the enone. Aliphatic enones react more sluggishly in this transformation; however, 3,4,5-trimethoxyphenylboronic acid may be used as a more efficient nucleophilic partner to circumvent this limitation.

Application of this transformation to the ripostatin A epoxide fragment 5 allows installation of the $\mathrm{C} 13$ hydroxy group via conjugate addition to the $\delta$-hydroxy- $\alpha, \beta$-enone 49 (Figure 5 ). Although the diastereoselectivity of this reaction using substrates with a chiral center at the hydroxy group had not been investigated in the published study, substitution at the carbinol position was reportedly well tolerated for the reaction using $\gamma$-hydroxy- $\alpha, \beta$-enones. Although the presence of chirality at the $\delta$-position allows for diastereoselective intramolecular oxy-Michael addition of hemiacetal-derived alkoxides into $\alpha, \beta$ unsaturated esters, the extension of this reaction to ketones was not successful [53]. In turn, we intended to prepare 49 by hydrometalation of $\mathbf{5 0}$ and addition into aldehyde $\mathbf{4 7}$.

To this end, $(R)$-glycidol was protected as the para-methoxybenzoate ether to give the PMB glycidol 52 (Scheme 13), in which the configuration is now assigned as $(S)$. Opening the epoxide of $\mathbf{5 2}$ with the ethylenediamine complex of lithium acetylide in a 1:1 THF/DMSO solvent mixture at $0{ }^{\circ} \mathrm{C}$ allowed the terminal alkyne to be accessed in $84 \%$ yield without rearrangement to the internal alkyne. Silyl protection afforded alkyne 50, which was prone to decomposition upon extended storage, even at $-20{ }^{\circ} \mathrm{C}$.

Hydrozirconation of alkyne $\mathbf{5 0}$ with Schwartz's reagent [54,55] was followed by transmetallation to zinc and nonselective addition into aldehyde 47. Oxidation of the resulting allylic alcohol mixture afforded the enone 53. Prior to the key oxy-Michael addition, it was necessary to remove the tert-butyldimethylsilyl protecting group. Use of TBAF under buffered (acetic acid) or unbuffered conditions proved sluggish and somewhat lowyielding, typically $\sim 50 \%$. Various other promoters led to decomposition $\left(\mathrm{BF}_{3} \cdot \mathrm{OEt}_{2}\right)$ or low conversion $(\mathrm{CsF})$; however, a modest improvement in yield was noted with the use of $1 \% \mathrm{HCl}$ in $\mathrm{MeOH}$ (with a small amount of THF to dissolve the starting material).

The oxy-Michael addition with chiral thiourea and phenylboronic acid proceeded to give a single diastereomer; however, after $48 \mathrm{~h}$ at $50{ }^{\circ} \mathrm{C}$, only $17 \%$ of the syn diol was formed, and $56 \%$ of the starting material was re-isolated. Under the modified conditions for less reactive aliphatic aldehydes using 3,4,5trimethoxyphenylboronic acid, we were unable to isolate the desired diol from the reaction mixture. Since the oxy-Michael substrate derived from $\mathbf{5 3}$ contains an existing stereocenter at the directing hydroxy group, we also attempted to carry out the
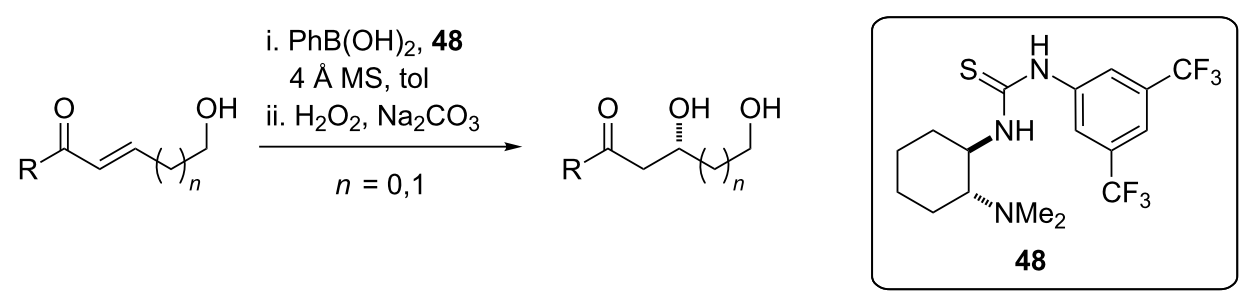

Scheme 12: Oxy-Michael addition to $\delta$-hydroxy- $\alpha, \beta$-enones.

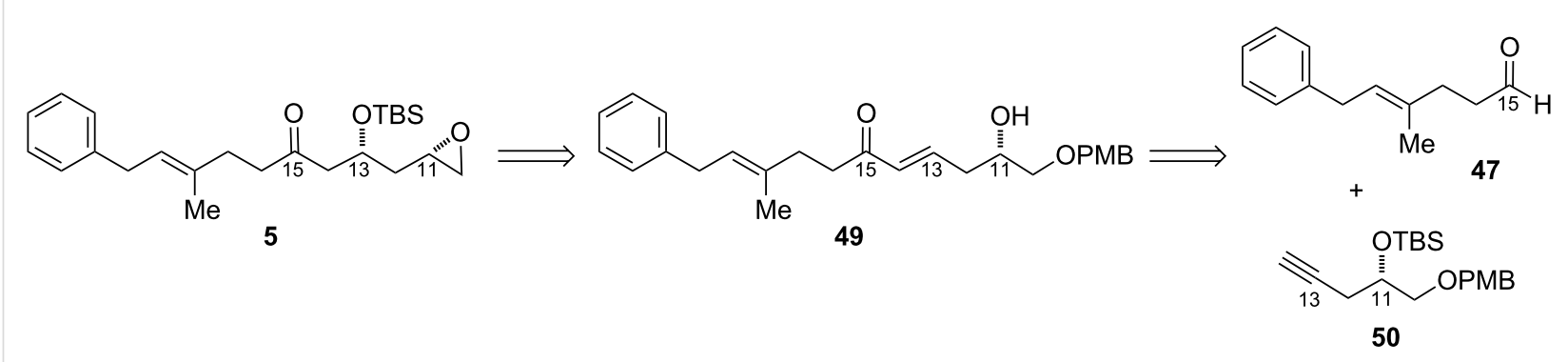

Figure 5: Revised retrosynthesis of epoxide 5 . 


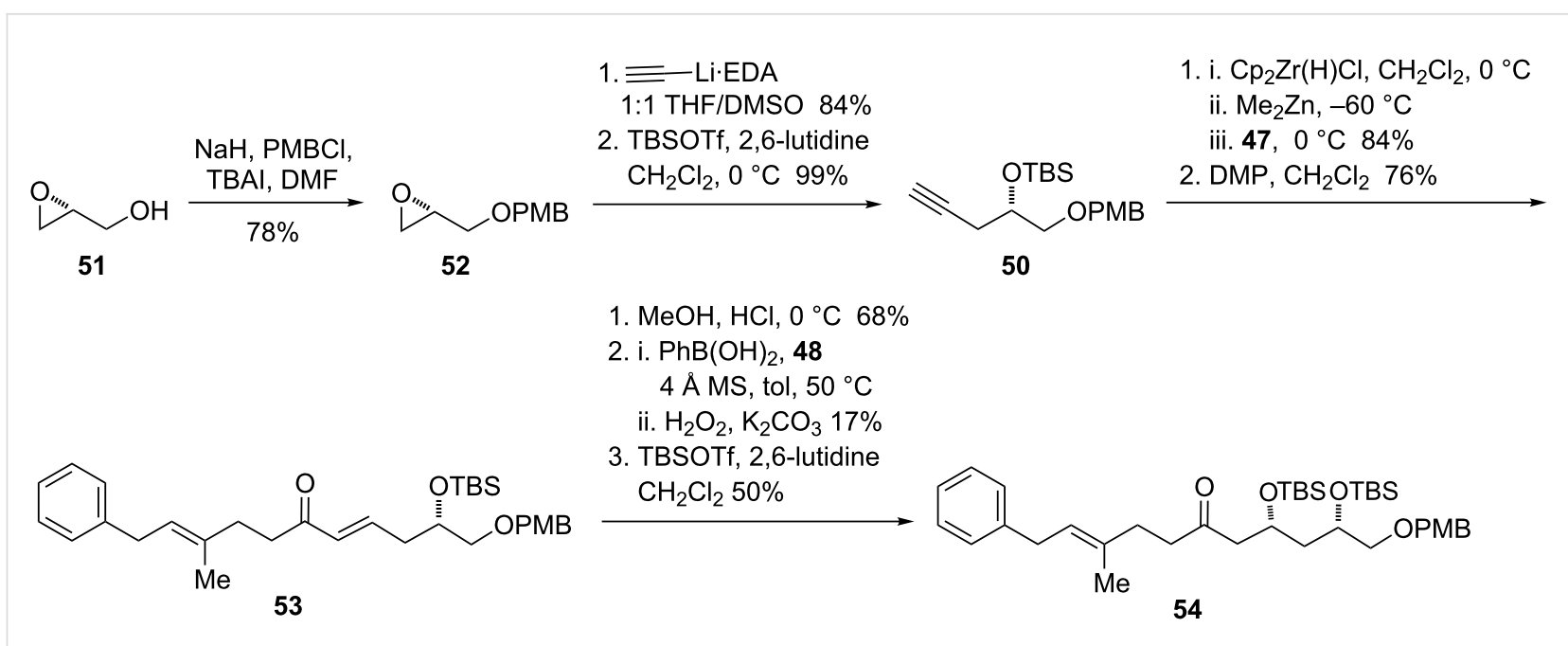

Scheme 13: Synthesis of functionalized ketone by oxy-Michael addition.

reaction with diisopropylamine as a substitute for the thiourea catalyst. This modification afforded both the syn and anti diols in roughly a $1: 1$ ratio and a combined yield of $40-45 \%$, albeit without recovery of starting material. The syn and anti diastereomers could be separated by repeated silica gel chromatography, and the desired syn diol was converted to the bis-silylated compound 54.

However, attempted oxidative deprotection of the PMB ether of $\mathbf{5 4}$ with DDQ led to destruction of the material. It seems likely that this is again due to the presence of the allylic/benzylic site in the molecule, although no individual decomposition products could be identified. Although it is possible that further screening of deprotection conditions might have allowed us to move forward with this route, the modest yields and long reaction time of the oxy-Michael addition severely limited material throughput. In order to proceed with the synthesis, we needed a more robust route, with the following criteria: (1) no protecting groups requiring oxidative cleavage, and (2) introduction of the C13 hydroxy group at an early stage.

\section{lodocyclization approaches to epoxide}

In the preparation of model epoxide $\mathbf{2 8}$, iodocyclization was used to introduce oxygenation in a stereoselective fashion from a chiral homoallylic alcohol. Applying this disconnection, we hypothesized that we might be able to introduce the epoxide functional group of 5 by iodocyclization of the tert-butyl carbonate 55 (Figure 6). Although the additional double bond in this substrate presents a potential site for competing reaction pathways, we were encouraged by a report by Bartlett in which the iodocyclization of the tert-butyl carbonate derivative of 1,7 octadien-4-ol afforded exclusively the 6-membered carbonate derivative, with product arising from cyclization onto the more distant double bond not detected [56]. We set out to access 55 from deprotonation of methyl ketone $\mathbf{5 7}$ on the less hindered side and alkylation with bromide $\mathbf{5 6 .}$

The $E$-allylic bromide was prepared rapidly, albeit in modest yield, with an Appel reaction [57] of the known allylic alcohol [58]. To synthesize ketone 57, we opted to utilize an asymmetric aldol reaction to set the stereochemistry of the $\beta$-hydroxy<smiles>C=C=CC(=O)O[C@H](C=C=C)CC(=O)CC(=O)/C(C)=C/Cc1ccccc1</smiles>

Figure 6: Retrosynthesis by using iodocylization to introduce the epoxide. 
group. Since the report of Evans's diastereoselective asymmetric aldol reaction using the boron enolates of $\mathrm{N}$-acyloxazolidinones [59], numerous chiral-auxiliary-based methods have been developed for the synthesis of $s y n$ - or anti-propionate aldol units. However, many of these auxiliaries, including the Evans oxazolidinones, fail to give high stereoselectivities when employed in acetate aldol reactions [60]. Of the methods available, we selected Sammakia's boron enolate-based strategy using the $N$-acetylthiazolidinethione $\mathbf{5 8}$ (Scheme 14) for its high reported diastereoselectivity with aliphatic aldehydes and its avoidance of toxic tin reagents [61].

The reaction of the brightly colored $\mathbf{5 8}$ with but-3-enal proceeded in moderate yield, with an initial diastereoselectivity around 10:1, with further enhancement following silyl protection and purification. Although the silylated compound $\mathbf{6 0}$ proved to be reluctant to form the Weinreb amide, microwave irradiation allowed this process to proceed on a reasonable time scale. Grignard addition to the Weinreb amide afforded ketone 57.

Unfortunately, attempts to unite ketone 57 and bromide 56 via alkylation were unsuccessful. Although deprotection at the lesssubstituted site of the methyl ketone using LDA was verified in a deuterium quench experiment, the alkylation did not proceed at temperatures from $-78{ }^{\circ} \mathrm{C}$ to $0{ }^{\circ} \mathrm{C}$. While the ketone was re-isolated cleanly following the reaction, the bromide was converted to a mixture of olefinic compounds. Faced with the difficulty of forming the $\mathrm{C} 16-\mathrm{C} 17$ bond by alkylation, we considered potential routes arising from retrosynthetic disconnection of the $\mathrm{C} 15-\mathrm{C} 16$ bond (Figure 7). It was recognized that reaction of the enolate of ester $\mathbf{4 5}$, a compound previously synthesized in just two steps, and subsequent oxidation could give the $\beta$-ketoester 61. Decarboxylation of this compound would provide rapid access to the key iodocyclization substrate 55.

Aldehyde 62 was prepared by reduction of the thiazolidinethione 60 with DIBAL-H (Scheme 15). Treatment of the ester with LDA, followed by trapping with the aldehyde, afforded the aldol adduct as a mixture of up to four possible diastereomers. This was then oxidized under Ley's conditions [62] to the $\beta$-ketoester $\mathbf{6 1}$, itself a mixture of two diastereomers.

Initially, we attempted to induce decarboxylation of $\mathbf{6 1}$ by treatment with $\mathrm{LiOH}$ in a 1:1 water/THF mixture. No reaction was observed at room temperature, but heating to $70{ }^{\circ} \mathrm{C}$ resulted in elimination of the $\beta$-siloxy group. The Krapcho reaction offers an essentially neutral method for the decarboxylation of baseand acid-sensitive substrates [63]. Under these conditions (sodium chloride in wet DMSO at elevated temperatures) the desired decarboxylation reaction proceeded, although only in modest yield (Scheme 16). Reduction of the temperature from $180{ }^{\circ} \mathrm{C}$ to $120^{\circ} \mathrm{C}$ led to much lower conversion, as expected, but did not improve mass recovery in the reaction. Somewhat more surprisingly, silyl deprotection with TBAF was also low yielding. Interestingly, when the order of these operations was reversed, the Krapcho conditions led to a complex product mix-

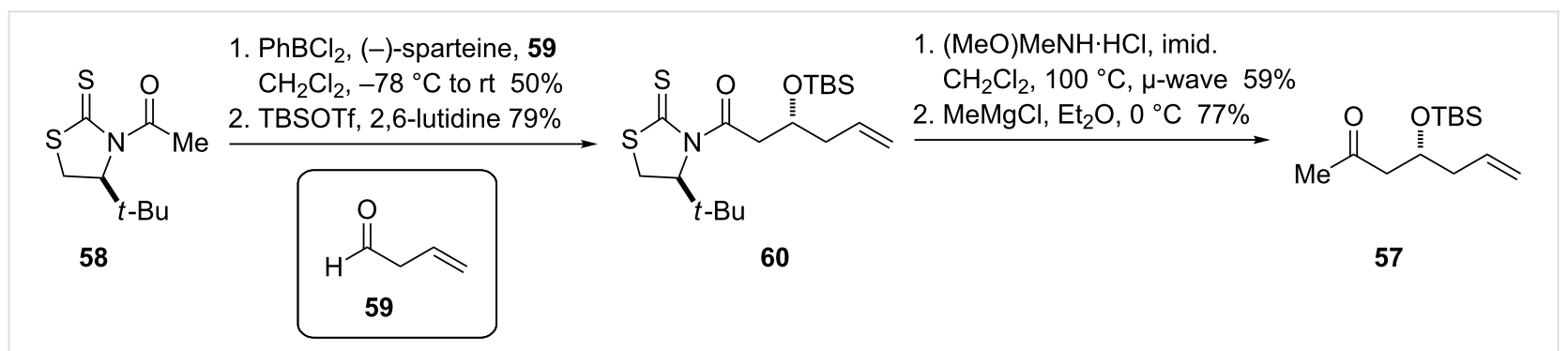

Scheme 14: Synthesis of ketone 57 using thiazolidinethione chiral auxiliary.

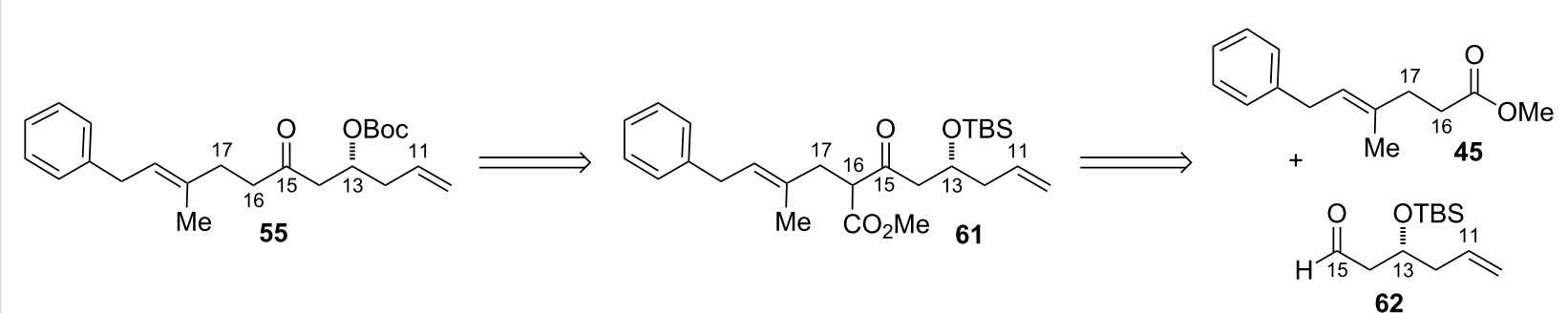

Figure 7: Retrosynthesis involving decarboxylation of a $\beta$-ketoester. 


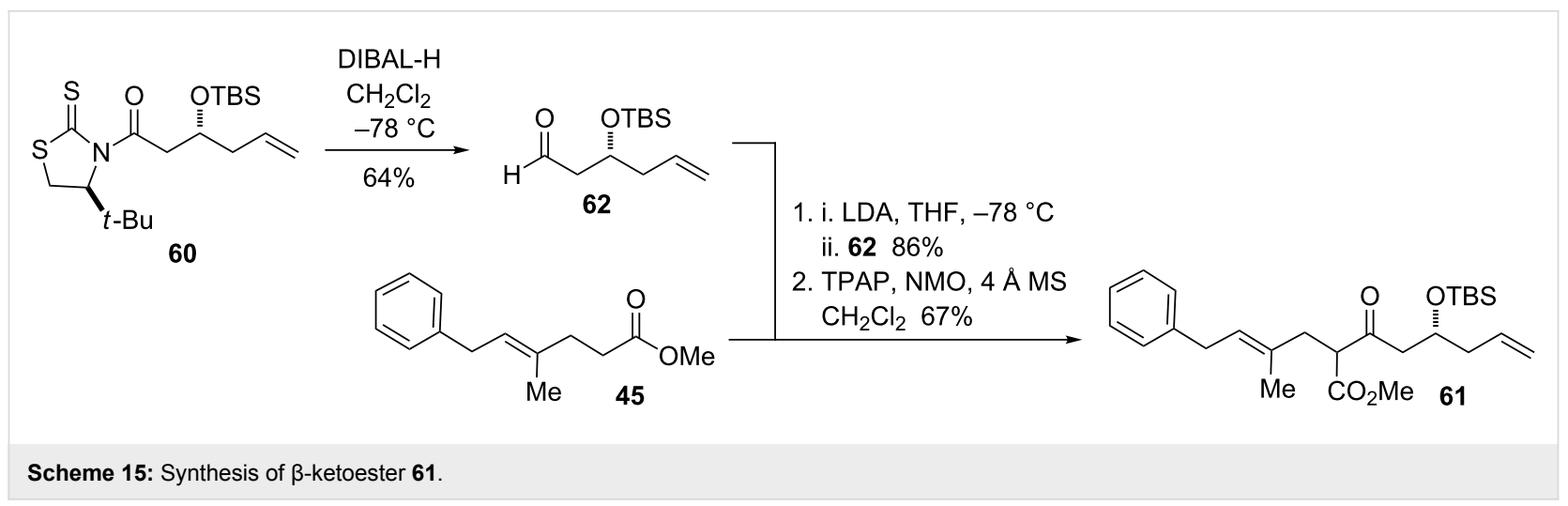

Scheme 15: Synthesis of $\beta$-ketoester 61

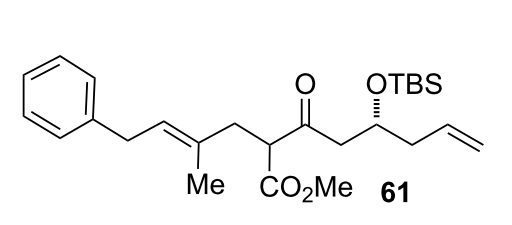

1. $\mathrm{NaCl}, \mathrm{H}_{2} \mathrm{O}$, DMSO

$\mu$-wave, $180{ }^{\circ} \mathrm{C} 44 \%$

2. TBAF, THF $41 \%$<smiles>C=CCC(O)CC(=O)CC/C(C)=C/Cc1ccccc1</smiles>

Scheme 16: Decarboxylation of 61 under Krapcho conditions.

ture, the major component of which appeared to be the dienone, formed by elimination and isomerization of the terminal olefin into conjugation.

We reasoned that the decarboxylation and silyl deprotection steps could be coupled into one operation by switching from the methyl ester to the 2-trimethylsilylethyl (TMSE) ester. Although there was concern that if the TBS group were removed first, the free hydroxy group would undergo elimination, it seemed likely that both deprotections would proceed at ambient temperature, which might circumvent this issue. Transesterification of methyl ester $\mathbf{4 5}$ to TMSE ester $\mathbf{6 4}$ proceeded in good yield, and following an analogous procedure for aldol reaction and oxidation the TMSE $\beta$-ketoester was obtained (Scheme 17). Treatment with an excess of TBAF in THF at room temperature overnight resulted in formation of the

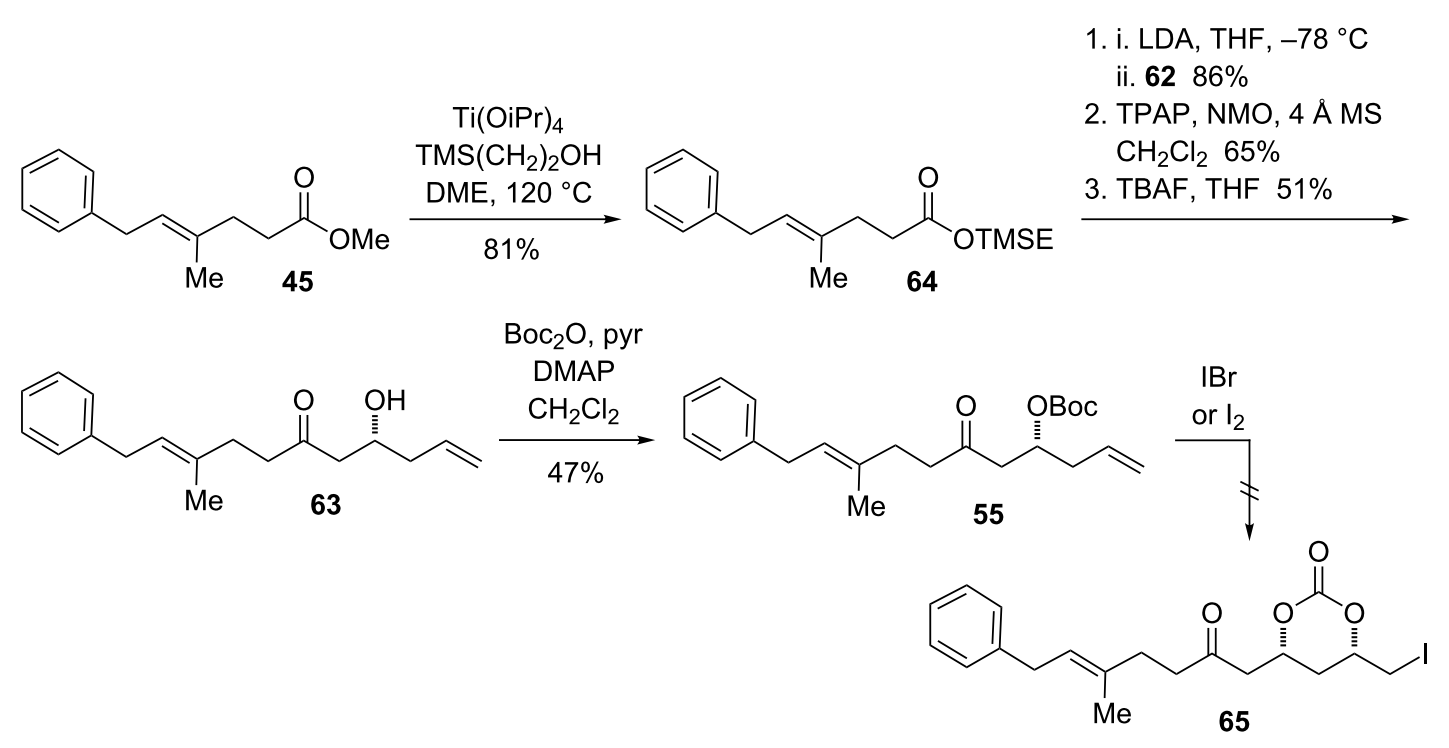


$\beta$-hydroxyketone 63. Although the yield for this transformation remained moderate, it was higher than that obtained for either of the individual steps from the methyl series that it replaced.

The cleavage of TMSE $\beta$-ketoesters with TBAF $3 \mathrm{H}_{2} \mathrm{O}$ has been described in the literature as a chemoselective method for decarboxylation in the presence of other types of $\beta$-ketoesters [64] Comparable yields for the decarboxylation to form 63 were obtained with this reagent as with the anhydrous solution, or when the reaction was run in DMF instead of THF. The use of TAS-F (tris(dimethylamino)sulfonium trifluoromethylsilicate) was clearly inferior, leading to incomplete conversion and elimination. With TBAF, partial elimination could sometimes be observed; however, this typically occurred in less than $10 \%$. Given these results, it seems that the fluoride-mediated deprotection of TMSE $\beta$-ketoesters is deserving of further exploration and utilization as a method for the decarboxylation of sensitive synthetic intermediates.

Alcohol 63 was derivatized as the Boc carbonate, a reaction plagued by the formation of the carbonate arising from two molecules of 63. The ratio of Boc derivative to symmetrical carbonates is dependent on the acidity of the alcohol and not necessarily improved by increasing the stoichiometry of $\mathrm{Boc}_{2} \mathrm{O}$ [65]. Disappointingly, treatment of $\mathbf{5 5}$ with $\mathrm{IBr}$ or $\mathrm{I}_{2}$ led to exhaustive decomposition of the material. Similarly, attempts to convert the homoallylic olefin of $\mathbf{5 5}$ into the epoxide via directed oxidation with $\mathrm{VO}(\mathrm{acac})_{2}$ and TBHP again resulted in an intractable mixture of products.

While investigations into installing the epoxide via iodocyclization were ultimately not fruitful, in the course of this route an expeditious and perhaps underappreciated disconnection was identified in the construction of the $\mathrm{C} 15-\mathrm{C} 16$ bond via a simple aldol reaction, followed by TBAF-promoted decarboxylation to remove the ester. We concluded that selective reaction of the terminal olefin in the presence of the trisubstituted olefin was not a feasible proposition. Therefore, a substrate with oxygenation present at $\mathrm{C} 10$ and $\mathrm{C} 11$ from an early stage was needed as well.

\section{Acetonide approach to epoxide}

To obtain the key $\mathrm{C} 10-\mathrm{C} 11$ epoxide in $\mathbf{5}$ in stereoselective fashion from displacement of a leaving group at $\mathrm{C} 10$, a means for the selective formation of a syn-1,3-diol at C11 and C13 is required. Rychnovsky has demonstrated that alkylation of 4-cyano-1,3-dioxanes (cyanohydrin acetonides) constitutes a practical and valuable approach to syn-1,3-diol synthesis [66]. The lithiated cyanohydrin acetonides react as nucleophiles with alkyl, allyl, and propargyl halides, as well as with epoxides. Although the alkylation itself is highly stereoselective in favor of the axial nitrile, the $s y n$-1,3-diol stereochemistry is ultimately set in a subsequent reductive decyanation step. We planned to synthesize 5 by reaction of the cyanohydrin acetonide 67 with the epoxide electrophile 66 (Figure 8) [67].

The dimethyl derivative of L-malic acid was chemoselectively reduced with borane-dimethylsulfide and sodium borohydride to afford diol 69 (Scheme 18) [68]. The primary alcohol was protected as the TIPS ether, and the secondary alcohol subsequently converted to the TMS ether. Reduction with DIBAL-H afforded the aldehyde $\mathbf{7 1}$ without over-reduction to the alcohol. Acetonide formation proceeded smoothly to give $\mathbf{6 7}$ as an inconsequential mixture of diastereomers. However, attemps to alkylate the lithiated anion of $\mathbf{6 7}$ with epoxide $\mathbf{6 6}$ led only to recovery of starting material. Interestingly, although alkylations of the acetonide are known to be stereoselective, protonation does not appear to be, as a cis and trans mixture was obtained from the attempted reaction of a single acetonide diastereomer.

In the course of investigating why $\mathbf{6 6}$ and $\mathbf{6 7}$ failed to react, attempts were made to trap the anion of $\mathbf{6 7}$ with a more reactive electrophile. Allyl bromide reacted rapidly, affording the product $\mathbf{7 3}$ as a single diastereomer (Scheme 19). The configuration of this compound, as well as subsequent compounds along this route, could be assigned as the 1,3-syn acetonide by analysis of the ${ }^{13} \mathrm{C}$ chemical shifts of the acetonide methyl groups [69]. It was recognized that conversion of this olefin to the aldehyde would provide an ideal electrophile for a revised $\beta$-ketoester decarboxylation strategy. To this end, reduction of the nitrile proceeded with the expected selectivity; this arises<smiles>CC(C)=CCc1ccccc1</smiles>

5

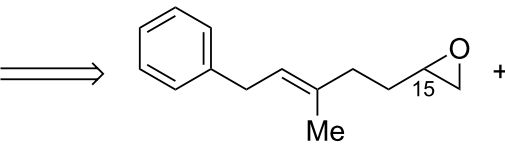

66

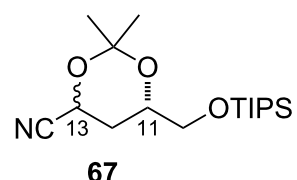

67 


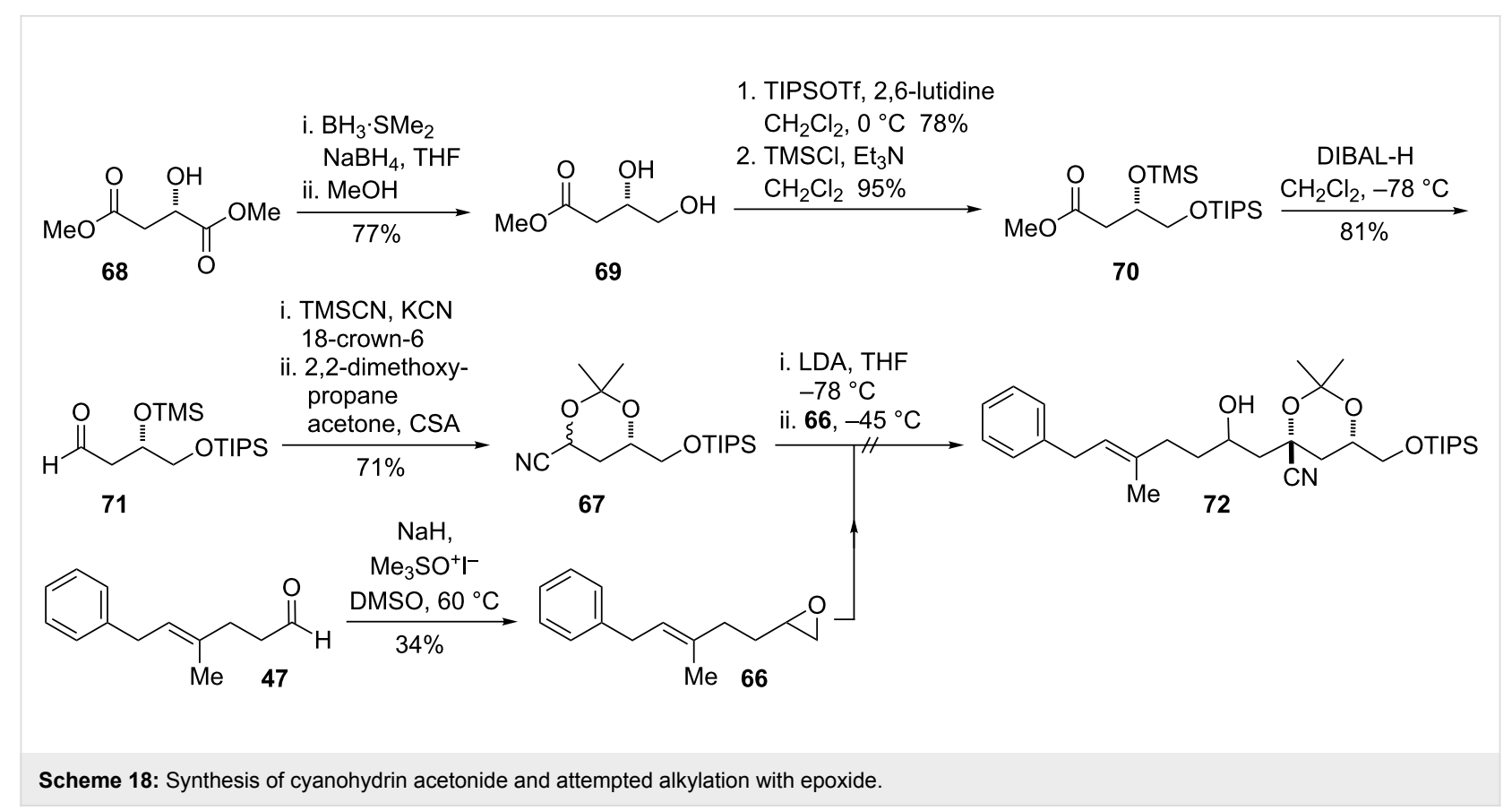<smiles>CC1(C)OC(CO[PbH2])CC1C#N</smiles>

67 i. LDA, THF, $-78{ }^{\circ} \mathrm{C}$
ii. allyl bromide
$\underset{53 \%, 71 \% \text { BRSM }}{\longrightarrow}$

(5)

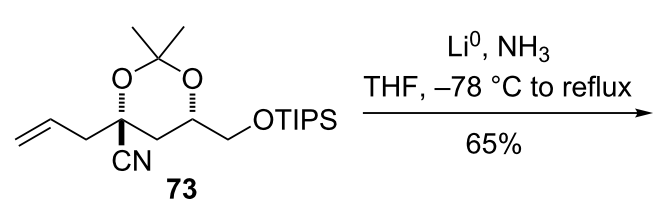

73<smiles>C=CCC1CC(C[OH+])OC(C)(C)O1</smiles>

74

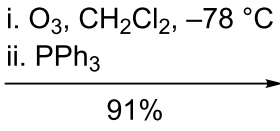$$
91 \%
$$

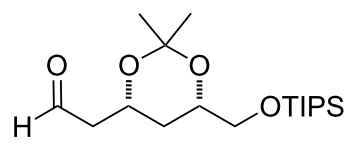

75

Scheme 19: Allylation of acetonide and conversion to aldehyde.

from equilibration of the intermediate radical to the more stable axial radical. It was essential to allow the reaction to warm under reflux due to the insolubility of the starting material in liquid ammonia. Ozonolysis of the pendant olefin afforded aldehyde 75 in high yield.

Following the prior procedure, the lithium enolate of TMS ester 64 was reacted with aldehyde 75 , and the mixture of diastereomeric alcohols was oxidized to the $\beta$-ketoester $\mathbf{7 6}$ (Scheme 20). This substrate did not appear to be prone to elimination, and treatment of the $\beta$-ketoester with TBAF in THF provided the decarboxylated and deprotected alcohol 77. The primary alcohol could be converted to the tosylate $\mathbf{7 8}$ in good yield with tosyl chloride, triethylamine, and trimethylamine hydrochloride as the catalyst.
The alcohol $\mathbf{7 7}$ and tosylate $\mathbf{7 8}$ contain all of the carbon atoms of epoxide fragment $\mathbf{5}$ in the correct oxidation state. The remaining steps required to access the epoxide consist of acetonide deprotection, displacement of the tosylate or another appropriate leaving group to obtain the terminal epoxide, and silyl protection.

\section{Conclusion}

Nickel-catalyzed reductive coupling methodologies are an attractive fragment coupling strategy for the synthesis of complex natural products. The formation of sensitive skipped diene units in this context remains largely an unsolved problem for organic chemistry, but reactions for the rearrangement of vinylcyclopropanes present an intriguing avenue for exploration. To facilitate future studies in this vein, a cyclopropylenyne corres- 


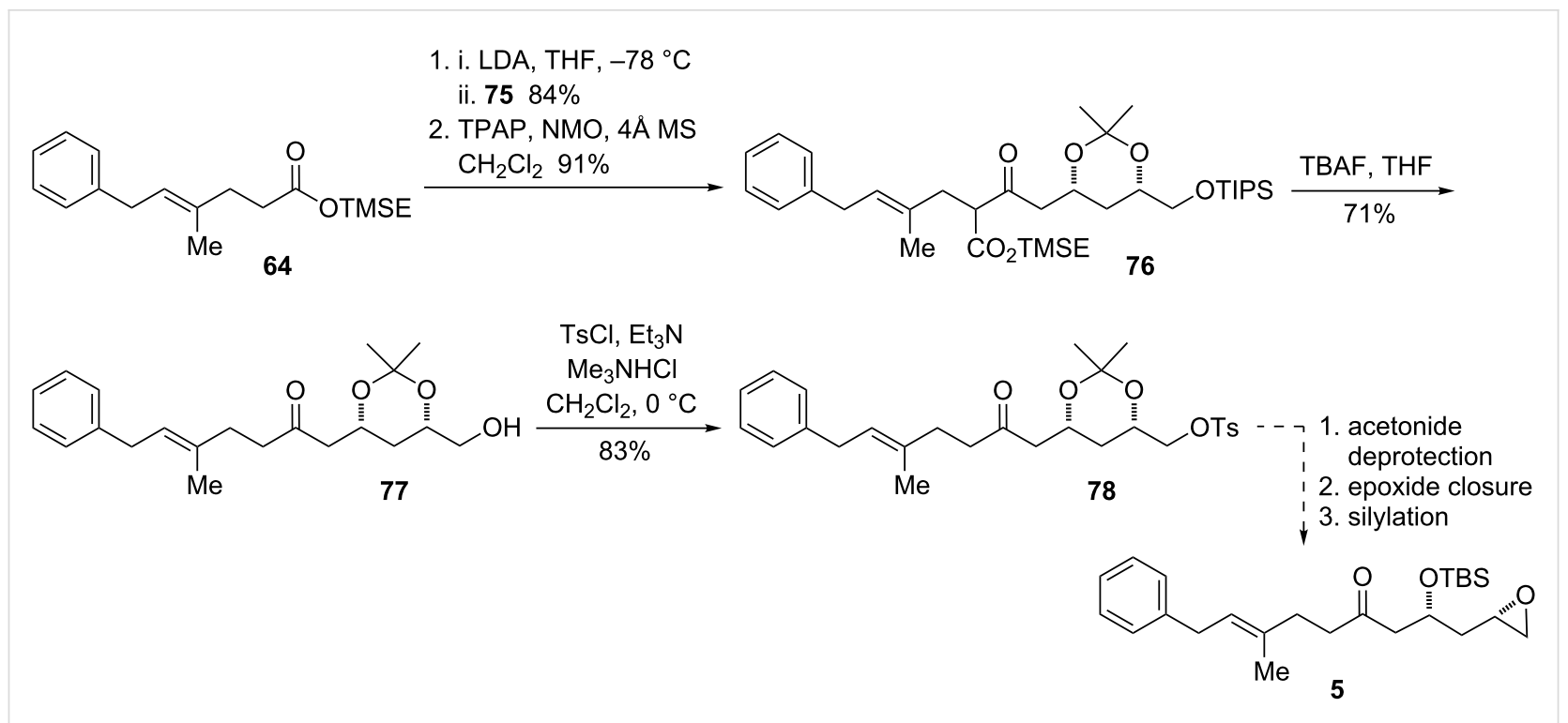

Scheme 20: Synthesis of the epoxide precursor by an aldol-decarboxylation sequence.

ponding to the $\mathrm{C} 1-\mathrm{C} 9$ carbons of ripostatin $\mathrm{A}$ was synthesized in ten steps and up to $35 \%$ yield, and was shown to be a viable substrate in a nickel-catalyzed coupling reaction. The lack of complete regioselectivity in this transformation highlights that the factors governing selectivity in this reaction are more complex and more substrate dependent than initially anticipated.

Several strategies for synthesis of the $\mathrm{C} 10-\mathrm{C} 26$ epoxide fragment were examined, including dithiane linchpin coupling, oxyMichael addition to an enone, and iodocyclization methods. Fluoride-promoted decarboxylation of TMSE esters was identified as a mild strategy enabling simple aldol reactions for the construction of the $\mathrm{C} 15-\mathrm{C} 16$ bond. Allylation and reductive decyanation of a lithiated cyanohydrin acetonide was used to set the $\mathrm{C} 13$ stereocenter. Additional efforts are needed to convert a fully oxygenated, ketone-containing triol into the critical epoxide fragment and to investigate the rearrangement of reductive coupling products.

\section{Supporting Information}

\section{Supporting Information File 1}

Experimental procedures and characterization data for newly synthesized compounds.

[http://www.beilstein-journals.org/bjoc/content/ supplementary/1860-5397-9-175-S1.pdf]

\section{Acknowledgements}

The authors gratefully acknowledge the support of the MIT Department of Chemistry Instrumentation Facility, including
Dr. Jeff Simpson for NMR assistance and Li Li for obtaining HRMS data, and Dr. Norman Lee of the Boston University Chemical Instrumentation Center for obtaining HRMS data. The National Institute of General Medical Sciences and Novartis provided funding for the research described.

\section{References}

1. Irschik, H.; Augustiniak, H.; Gerth, K.; Höfle, G.; Reichenbach, H. J. Antibiot. 1995, 48, 787-792. doi:10.7164/antibiotics.48.787

2. Augustiniak, H.; Irschik, H.; Reichenbach, H.; Höfle, G. Liebigs Ann. 1996, 1657-1663. doi:10.1002/jlac.199619961026

3. Chang, S.; Sievert, D. M.; Hageman, J. C.; Boulton, M. L.; Tenover, F. C.; Downes, F. P.; Shah, S.; Rudrick, J. T.; Pupp, G. R.; Brown, W. J.; Cardo, D.; Fridkin, S. K. N. Engl. J. Med. 2003, 348, 1342-1347. doi:10.1056/NEJMoa025025

4. The text in [2] refers to the alkene geometry as $(2 Z, 5 E, 8 E)$; this is assumed to be a typographical error.

5. Kujat, C.; Bock, M.; Kirschning, A. Synlett 2006, 419-422. doi:10.1055/s-2006-926263

6. Winter, P.; Hiller, W.; Christmann, M. Angew. Chem., Int. Ed. 2012, 51, 3396-3400. doi:10.1002/anie.201108692

7. Tang, W.; Prusov, E. V. Angew. Chem., Int. Ed. 2012, 51, 3401-3404. doi:10.1002/anie.201108749

8. Glaus, F.; Altmann, K.-H. Angew. Chem., Int. Ed. 2012, 51 , 3405-3409. doi:10.1002/anie.201200871

9. Tang, W.; Prusov, E. V. Org. Lett. 2012, 14, 4690-4693. doi:10.1021/ol302219x

10. Bordwell, F. G.; Drucker, G. E.; Fried, H. E. J. Org. Chem. 1981, 46, 632-635. doi:10.1021/jo00316a032

The $\mathrm{p} K_{\mathrm{a}}$ of 1,4-pentadiene in DMSO is approximately 35.

11. McMahon, T. B.; Kebarle, P. J. Am. Chem. Soc. 1974, 96, 5940-5942. doi:10.1021/ja00825a044

The bond dissociation energy of the doubly allylic $\mathrm{C}-\mathrm{H}$ bonds in 1,4-pentadiene has been measured as $68.5 \mathrm{kcal} / \mathrm{mol}$. 
12. Trost, B. M.; Probst, G. D.; Schoop, A. J. Am. Chem. Soc. 1998, 120, 9228-9236. doi:10.1021/ja981540n

13. Moreau, B.; Wu, J. Y.; Ritter, T. Org. Lett. 2009, 11, 337-339. doi:10.1021/ol802524r

14. Morten, C. J.; Jamison, T. F. Tetrahedron 2009, 65, 6648-6655. doi:10.1016/j.tet.2009.05.074

15. Matsubara, R.; Jamison, T. F. J. Am. Chem. Soc. 2010, 132, 6880-6881. doi:10.1021/ja101186p

16. McCammant, M. S.; Liao, L.; Sigman, M. S. J. Am. Chem. Soc. 2013, 135, 4167. doi:10.1021/ja3110544

17. Molinaro, C.; Jamison, T. F. J. Am. Chem. Soc. 2003, 125, 8076-8077. doi:10.1021/ja0361401

18. Miller, K. M.; Luanphaisarnnont, T.; Molinaro, C.; Jamison, T. F. J. Am. Chem. Soc. 2004, 126, 4130-4131. doi:10.1021/ja0491735

19. Murakami, M.; Nishida, S. Chem. Lett. 1979, 8, 927-930. doi:10.1246/cl.1979.927

20. Ryu, I.; Ikura, K.; Tamura, Y.; Maenaka, J.; Ogawa, A.; Sonoda, N. Synlett 1994, 941-942. doi:10.1055/s-1994-23057

21. Zuo, G.; Louie, J. Angew. Chem., Int. Ed. 2004, 43, 2277-2279. doi:10.1002/anie.200353469

22. Ellis, R. J.; Frey, H. M. Proc. Chem. Soc., London 1964, 221.

23. Daub, J. P.; Berson, J. A. Tetrahedron Lett. 1984, 25, 4463-4466. doi:10.1016/S0040-4039(01)81467-2

24. Parziale, P. A.; Berson, J. A. J. Am. Chem. Soc. 1990, 112, 1650-1652. doi:10.1021/ja00160a066

25. Parziale, P. A.; Berson, J. A. J. Am. Chem. Soc. 1991, 113, 4595-4606. doi:10.1021/ja00012a032

26. Lin, Y.-L.; Turos, E. J. Org. Chem. 2001, 66, 8751-8759. doi:10.1021/jo0103221

27. Wilson, S. R.; Zucker, P. A. J. Org. Chem. 1988, 53, 4682-4693. doi:10.1021/j000255a007

28. Braddock, D. C.; Badine, D. M.; Gottschalk, T. Synlett 2001, 1909-1912. doi:10.1055/s-2001-18736

29. Braddock, D. C.; Badine, D. M.; Gottschalk, T.; Matsuno, A.; Rodriguez-Lens, M. Synlett 2003, 345-348. doi:10.1055/s-2003-37111

30. Braddock, D. C.; Matsuno, A. Synlett 2004, 2521-2524. doi:10.1055/s-2004-834802

31. Macklin, T. K.; Micalizio, G. C. Nat. Chem. 2010, 2, 638-643. doi:10.1038/nchem.665

32. Peterson, D. J. J. Org. Chem. 1968, 33, 780-784. doi:10.1021/jo01266a061

33. Corey, E. J.; Chaykovsky, M. J. Am. Chem. Soc. 1962, 84, 867-868. doi:10.1021/ja00864a040

34. Corey, E. J.; Chaykovsky, M. J. Am. Chem. Soc. 1965, 87, 1353-1364. doi:10.1021/ja01084a034

35. Furukawa, J.; Kawabata, N.; Nishimura, J. Tetrahedron Lett. 1966, 7, 3353-3354. doi:10.1016/S0040-4039(01)82791-X

36. Takai, K.; Nitta, K.; Utimoto, K. J. Am. Chem. Soc. 1986, 108, 7408-7410. doi:10.1021/ja00283a046

37. Sonogashira, K.; Tohda, Y.; Hagihara, N. Tetrahedron Lett. 1975, 16, 4467-4470. doi:10.1016/S0040-4039(00)91094-3

38. Smith, A. B., III; Sfouggatakis, C.; Risatti, C. A.; Sperry, J. B.; Zhu, W.; Doughty, V. A.; Tomioka, T.; Gotchev, D. B.; Bennett, C. S.; Sakamoto, S.; Atasoylu, O.; Shirakami, S.; Bauer, D.; Takeuchi, M.; Koyanagi, J.; Sakamoto, Y. Tetrahedron 2009, 65, 6489-6509. doi:10.1016/j.tet.2009.04.003

39. Tokunaga, M.; Larrow, J. F.; Kakiuchi, F.; Jacobsen, E. N. Science 1997, 277, 936-938. doi:10.1126/science.277.5328.936

40. McCarren, P. R.; Liu, P.; Cheong, P. H.-Y.; Jamison, T. F.; Houk, K. N. J. Am. Chem. Soc. 2009, 131, 6654-6655. doi:10.1021/ja900701g
41. Liu, P.; McCarren, P.; Cheong, P. H.-Y.; Jamison, T. F.; Houk, K. N. J. Am. Chem. Soc. 2010, 132, 2050-2057. doi:10.1021/ja909562y

42. Huang, W.-S.; Chan, J.; Jamison, T. F. Org. Lett. 2000, 2, 4221-4223. doi:10.1021/ol006781q

43. Miller, K. M.; Huang, W.-S.; Jamison, T. F. J. Am. Chem. Soc. 2003, 125, 3442-3443. doi:10.1021/ja034366y

44. Byers, J. A. Unpublished results.

45. Fischer, M.-R.; Kirschning, A.; Michel, T.; Schaumann, E. Angew. Chem., Int. Ed. Engl. 1994, 33, 217-218. doi:10.1002/anie.199402171

46. Tietze, L. F.; Geissler, H.; Gewert, J. A.; Jakobi, U. Synlett 1994, 511-512. doi:10.1055/s-1994-22908

47. Smith, A. B., III; Boldi, A. M. J. Am. Chem. Soc. 1997, 119, 6925-6926. doi:10.1021/ja970371o

48. Schaumann, E.; Kirschning, A. Synlett 2007, 177-190. doi:10.1055/s-2007-968023

49. Kirschning, A.; Kujat, C.; Luiken, S.; Schaumann, E. Eur. J. Org. Chem. 2007, 2387-2400. doi:10.1002/ejoc.200601003

50. Johnson, W. S.; Werthemann, L.; Bartlett, W. R.; Brocksom, T. J.; Li, T.-T.; Faulkner, D. J.; Petersen, M. R. J. Am. Chem. Soc. 1970, 92, 741-743. doi:10.1021/ja00706a074

51. Smith, A. B., III; Adams, C. M. Acc. Chem. Res. 2004, 37, 365-377. doi:10.1021/ar030245r

52. Li, D. R.; Murugan, A.; Falck, J. R. J. Am. Chem. Soc. 2008, 130, 46-48. doi:10.1021/ja076802c

53. Evans, D. A.; Gauchet-Prunet, J. A. J. Org. Chem. 1993, 58 , 2446-2453. doi:10.1021/jo00061a018

54. Wailes, P. C.; Weingold, H. J. Organomet. Chem. 1970, 24, 405-411. doi:10.1016/S0022-328X(00)80281-8

55. Hart, D. W.; Schwartz, J. J. Am. Chem. Soc. 1974, 96, 8115-8116. doi:10.1021/ja00833a048

56. Bartlett, P. A.; Meadows, J. D.; Brown, E. G.; Morimoto, A.; Jernstedt, K. K. J. Org. Chem. 1982, 47, 4013-4018. doi:10.1021/jo00142a002

57. Appel, R. Angew. Chem., Int. Ed. Engl. 1975, 14, 801-811. doi:10.1002/anie.197508011

58. Malkov, A. V.; Czemeryz, L.; Malyshev, D. A. J. Org. Chem. 2009, 74, 3350-3355. doi:10.1021/jo900294h

59. Evans, D. A.; Bartroli, J.; Shih, T. L. J. Am. Chem. Soc. 1981, 103, 2127-2129. doi:10.1021/ja00398a058

60. Braun, M. Angew. Chem., Int. Ed. Engl. 1987, 26, 24-37. doi:10.1002/anie.198700241

61. Zhang, Y.; Phillips, A. J.; Sammakia, T. Org. Lett. 2004, 6, $23-25$. doi:10.1021/ol036020y

62. Ley, S. V.; Norman, J.; Griffith, W. P.; Marsden, S. P. Synthesis 1994, 639-666. doi:10.1055/s-1994-25538

63. Krapcho, A. P.; Lovey, A. J. Tetrahedron Lett. 1973, 14, 957-960. doi:10.1016/S0040-4039(00)72461-0

64. Knobloch, E.; Brückner, R. Synlett 2008, 1865-1869. doi:10.1055/s-2008-1078568

65. Basel, Y.; Hassner, A. J. Org. Chem. 2000, 65, 6368-6380. doi:10.1021/jo000257f

66. Sinz, C. J.; Rychnovsky, S. D. Top. Curr. Chem. 2001, 216, 51-92. doi:10.1007/3-540-44726-1_2

67. Rychnovsky, S. D.; Zeller, S.; Skalitzky, D. J.; Griesgraber, G. J. Org. Chem. 1990, 55, 5550-5551. doi:10.1021/jo00308a004 As the acetonide appears in the literature without spectroscopic data, we have therefore fully characterized this compound and its precursors. 
68. Saito, S.; Hasegawa, T.; Inaba, M.; Nishida, R.; Fujii, T.; Nomizu, S.; Moriwake, T. Chem. Lett. 1984, 13, 1389-1392.

doi:10.1246/cl.1984.1389

69. Rychnovsky, S. D.; Skalitzky, D. J. Tetrahedron Lett. 1990, 31, 945-948. doi:10.1016/S0040-4039(00)94399-5

The small A value of a nitrile means that it behaves as a hydrogen in ${ }^{13} \mathrm{C}$ acetonide analysis. The observed ${ }^{13} \mathrm{C}$ acetonide chemical shifts of 30.8 and $21.6 \mathrm{ppm}$ are consistent with the syn acetonide.

\section{License and Terms}

This is an Open Access article under the terms of the Creative Commons Attribution License

(http://creativecommons.org/licenses/by/2.0), which permits unrestricted use, distribution, and reproduction in any medium, provided the original work is properly cited.

The license is subject to the Beilstein Journal of Organic Chemistry terms and conditions:

(http://www.beilstein-journals.org/bjoc)

The definitive version of this article is the electronic one which can be found at: doi:10.3762/bjoc. 9.175 